Colloid and Interface Science

Elsevier Editorial System(tm) for Journal of

Manuscript Draft

Manuscript Number: JCIS-20-3387R1

Title: The effect of alginate composition on adsorption to calcium carbonate surfaces

Article Type: Full length article

Section/Category: C. Adsorption, Catalysis and Electrochemistry

Keywords: Calcium Carbonate; Calcite; Biomineralization; Alginate; Polysaccharides; Mannuronic Acid; Guluronic Acid; Adsorption; Neutron Reflection; Interfaces

Corresponding Author: Dr. Kathryn Louise Browning,

Corresponding Author's Institution: University of Copenhagen

First Author: Kathryn Louise Browning

Order of Authors: Kathryn Louise Browning; Isabella N Stocker, PhD; Philipp Gutfreund, PhD; Stuart M Clarke, PhD

Abstract: Bacterial anchoring to limestone rocks is thought to occur by selective adsorption of biomolecules found in the extracellular matrix, such as polysaccharides. Here we study the adsorbed structure of a model matrix polysaccharide, sodium alginate, at the calcite/water interface using neutron reflection (NR). Sodium alginate was found to form highly hydrated layers extending up to $350 \AA$ into solution at concentrations up to $2.5 \mathrm{ppm}$ (the inflection point of the adsorption isotherm). The adsorption of alginate was driven by dissolution of the calcite surface through complexation of free calcium ions. This was shown using two alginates with differing ratios of sugar residues. Alginates with a higher proportion of guluronic acid (G) have a higher affinity for calcium ions and were found to cause the surface to dissolve to a greater extent and to adsorb more at the surface when compared to alginates with a higher proportion of mannuronic acid (M). Adding magnesium to the high G alginate solution reduced dissolution of the surface and the adsorbed amount. In this work, we have shown that polysaccharide adsorption to sparingly soluble calcite interfaces is closely related to polymer conformation and affinity for free calcium ions in solution. 


\section{UNIVERSITY OF CAMBRIDGE}

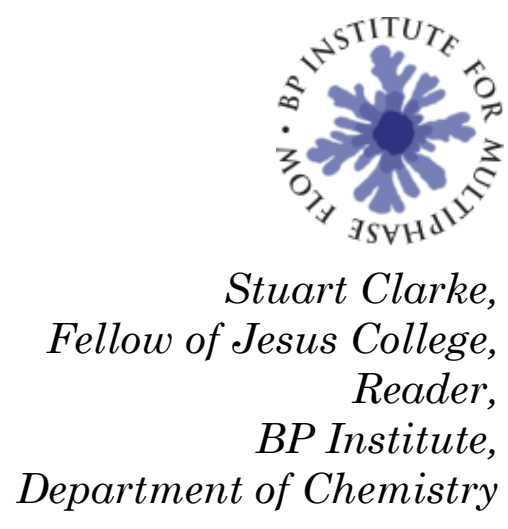

Stuart Clarke, Reader,

BP Institute,

Department of Chemistry

\section{Dear Professor Berti,}

Please find enclosed our manuscript on the adsorption of sodium alginate to calcite surfaces as studied by neutron reflection.

We believe this is the first report of biomolecule adsorption to calcite using this technique and as a result we are able to characterise the amount and structure of the adsorbed layer. In particular, the role of calcium binding and alginate composition is highlighted.

The Journal of Colloid and Interface Science has a long history of publishing neutron reflectivity of soft matter studies and has previously supported our earlier work on neutron reflectivity of calcite interfaces. We feel that this study will be of interest to your readers, particularly in related areas, such as biomineralisation.

This research has not been published elsewhere and does not contain any work being considered for other journals.

Please find below a list of possible reviewers.

\begin{tabular}{|c|c|c|}
\hline Name & Affiliation & Email \\
\hline $\begin{array}{c}\text { Professor Fiona } \\
\text { Meldrum }\end{array}$ & University of Leeds, UK & f.meldrum@leeds.ac.uk \\
\hline $\begin{array}{c}\text { Professor Susan Stipp } \\
\text { Professor Ralph } \\
\text { Mitchell }\end{array}$ & $\begin{array}{c}\text { Danmarks Tekniske Universitet, } \\
\text { Denmark }\end{array}$ & stipp@fysik.dtu.dk \\
\hline $\begin{array}{c}\text { Professor Neal } \\
\text { Skipper }\end{array}$ & Harvard University, USA & mitchell@seas.harvard.edu \\
\hline Professor Jian Lu & University of Manchester, UK & j.lu@manchester.ac.uk \\
\hline
\end{tabular}

If you require any further information please do not hesitate to contact me.

Yours Faithfully,

Stuart Clarke and Kathryn Browning

Jesus College,

Jesus lane,

Cambridge, CB5 8BL

Telephone: 01223765700

Fax: 01223765701

E-mail: stuart@bpi.cam.ac.uk 


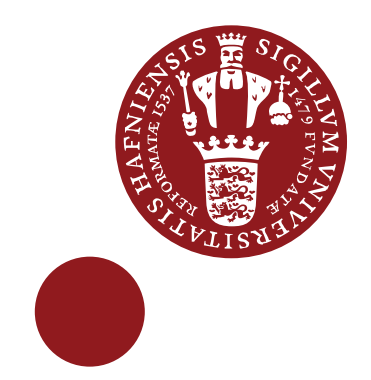

1 JULY 2020

Dear Professor Berti,

LEO FOUNDATION CENTRE FOR

CUTANEOUS DRUG DELIVERY

Thank you for your evaluation of our manuscript "The effect of alginate composition on adsorption to calcium carbonate surfaces" Ref: JCIS-203387.

We have addressed the comments raised by the editorial office and the reviewers below and made highlighted changes in the updated manuscript.

UNIVERSITY OF COPENHAGEN, UNIVERSITETSPARKEN 2,

COPENHAGEN 2100

\section{Reviewers' comments:}

DIR $\quad 4535332637$

Reviewer \#1: The authors report on the adsorption of sodium alginate on a

MOB 4542494825 calcite surface in water.

kathryn.browning@sund.ku.dk

They used a contrast series of neutron reflectometry measurements to compare adsorption of two alginate samples with low and high content of guluronic acid, concluding that alginates with a higher guluronic acid content adsorbed more.

I found this manuscript really well written, clear and convincing. The reflectometry measurements, which are central to the paper, were very well described. I would definitely recommend accepting this manuscript for publication, with minor revisions.

We thank the reviewer for his/her positive appraisal of our manuscript.

I noted the following recommendations. Those would help the reader understand the interpretation of the data a little better.

1-Page 10, Line 2: "Errors were calculated using the bootstrap error analysis $[\ldots]^{\prime \prime}$ 
Would it be possible to add a couple of lines describing what this method is?

Within the RasCAL program the Monte Carlo error is calculated by randomising the parameters within the set limits and calculating the best fit to the data, this is performed 100 times and the error is calculated from a histogram of obtained values.

The manuscript has been updated to read:

"Errors were calculated using the bootstrap error analysis in the RasCAL program, where random parameter values are generated and a fit performed 100 times to generate confidence intervals. The parameter errors were then used to calculate the error in adsorbed amount, assuming the maximum and minimum possible values." Page 9 Line 21 - Page 10 Line 2

2-Page 10, Line 4: "The SLDs [...] were_ALL_fixed according to the literature values (Table 1)." (Emphasis mine)

Table 1 is not part of the main manuscript. Table S1 is probably meant.

Minor clarity issue: This sentence is also confusing because it is followed by a statement that contradicts it. For clarity, it might be best to point out the literature SLDs in Table S1 and mention that these values were used whenever possible. Then the description of how the H2O SLD was determined can follow.

We thank the reviewer for noticing the mistake. This has been updated in the manuscript.

The manuscript has been updated to:

"The SLDs of substrate, subphase, and adsorbate were fixed, where possible, according to the literature values (Table S1)." Page 10 Lines 2-3

We have clarified that $\mathrm{H}_{2} \mathrm{O}$ contrast is a fitting parameter in the manuscript text as below:

"The two $\left(\mathrm{D}_{2} \mathrm{O}\right.$ and $\left.\mathrm{H}_{2} \mathrm{O}\right)$ data sets were fitted simultaneously using only two fitting variables, surface roughness and $\mathrm{H}_{2} \mathrm{O}$ contrast." Page 11 21-22

A footnote has also been added to Table $\mathrm{S} 1$ in the supporting information explaining that it was sometimes necessary to fit the $\mathrm{H}_{2} \mathrm{O}$ contrast. SI Page 2

3-Page 11, Line 4: "[...] this difference is close to the error [...]" 
This is not really true. Looking at Fig 2, the difference is definitely statistically significant. I don't think there's a problem with that. It wasn't clear why this needed to be brought up. I would suggest dropping the statement about the difference being close to the error.

We agree with the reviewer that the difference is significant, we have removed this sentence from the manuscript. Page 10 Line 16.

4- Page 14, Line 2. "The SLD of the subphase in the H2O was higher than the literature $[\ldots]^{\prime \prime}$

How was that SLD value determined? I notice that this value doesn't have an uncertainty, unlike most other model parameters.

The SLD value for $\mathrm{H}_{2} \mathrm{O}$ was determined by fitting the contrast as a parameter in a similar way to the other tabulated parameters such as surface roughness. Due to the lack of total reflection for contrasts that are lower than the substrate (Calcite $=4.69 \times 10^{-6} \AA^{-2}$ ) it is not possible to fix the contrast without fitting, however, we have found that the fit to the contrast is very robust as the intensity of reflection at low $\mathrm{Q}$ is not affected by the adsorbed layer at the surface. We obtain an error of $0.05 \times 10^{-6} \AA^{-2}$ for MVM and $0.07 \times 10^{-6} \AA^{-2}$ for MVG using the bootstrap error analysis described above and have added this value to the manuscript as below:

"The SLD of the subphase in the $\mathrm{H}_{2} \mathrm{O}$ was fitted to be higher $(2.28 \pm 0.05 \mathrm{x}$ $10^{-6} \AA^{-2}$ ) than the literature value of $-0.56 \times 10^{-6} \AA^{-2}$, due to incomplete exchange, as discussed above." Page 13 Line 15 - Page 14 Line 1

We have also stated the fitted $\mathrm{H}_{2} \mathrm{O}$ contrast for the $\mathrm{MVG}$ alginate with error

"The SLD of the $\mathrm{H}_{2} \mathrm{O}$ contrast was again found to be higher than literature $\left(3.28 \pm 0.07 \times 10^{-6} \AA^{-2}\right)$ as for MVM alginate." Page 14 Lines 7-8

\section{5-Description of the fitted results}

The reflectometry modeling is well described. Figure 5 is very good. To be able to better judge the fits, it would be nice to see the fitted SLD distributions. This way the reader can visually assess how the roughness and adsorbed layer were modeled. 
We thank the reviewer for his/her positive comment. In the manuscript we avoided using SLD profiles as they are often only useful to experts in the field, hence we chose instead to show volume fractions. We agree that it is useful to equate the fits to the calculated scattering length density profiles and have included them as new figures in the supporting information (Figure S3). SI Page 4

Sentences have been added to the manuscript to point to this:

"Corresponding SLD profiles are provided in the supporting information (Figure S3).” Page 12 Line 15

Reviewer \#2: The authors present interesting fundamental studies on the formation of alginate coatings onto calcium carbonate surfaces. Neutron reflection studies have been applied to study the roughness, the thickness and the amount of adsorbed alginates. These data should be useful to researchers working with alginate based coatings, but I provide a number of comments which should improve the quality of this work further.

We thank the reviewer for his/her positive appraisal of our manuscript.

Page 4: in the last paragraph, the authors discuss bacteria and their role in production of alginates. This paragraph appears not to be connected with previous or next paragraphs.

Having reread the introduction with this in mind we can see that the flow is not ideal. In order to better link the red thread through the introduction we have moved this paragraph above the previous one. The flow now discusses the bacteria as a potential source of alginate, describes the bacterial alginates and then talks more about the physics behind why the different alginates have different properties. Page 4 Lines 4-10

This is a nice fundamental study, but I wonder why the authors have not used traditionally applied infrared spectroscopy to confirm the presence of materials. Also, often the adsorption studies are done with atomic force microscopy (AFM) visualization of the surface. It would be helpful to understand the complete picture, i.e. the roughness of the surface. It would have helped to confirm the presence of calcite and it would have ideally fit into conclusions drawn from Figure $5(C)$.

If AFM is not available, perhaps some electron microscopy scans can be added, again, to visualize the surface. 
We have chosen in this study to focus on the use of neutron reflectivity as it provides unparalleled information on the buried surface structure parallel to the interface, through this we are able to confirm the presence of alginate at the surface and determine a surface roughness over the whole crystal surface. We tested the hypothesis of pure surface roughening and pure adsorption but the only way to fit to the data adequately was to assume both surface roughening and adsorption. Hence we are reasonably convinced on the presence of the materials.

We are currently attempting to develop surface IR of calcite water interfaces by combining SFG/RAIRS, however, this is non-trivial due to the birefringence and peak ratio being affected by crystallographic axis orientation. We hope to include this in future work but do not feel that it would add significant findings to the current study.

Perry et. al. studied the AFM surface in contact with alginic acid in a standalone study (Perry IV, T. D.; Duckworth, O. W.; McNamara, C. J.; Martin, S. T.; Mitchell, R. Effects of the Biologically Produced Polymer Alginic Acid on Macroscopic and Microscopic Calcite Dissolution Rates. Environ. Sci. Technol. 2004, 38 (11), 3040-3046. https://doi.org/10.1021/es035299a.). Although they only used one type of alginic acid, they were able to study the etch pit formation and found that the obtuse steps of the retreat rate increased dramatically upon interaction with alginate (Page 20 Lines 13-18). Although it would be nice to include information on the effects of MVM and MVG to the lateral surface roughening we feel that this would require a large amount of method development and provide only an incremental increase in knowledge of our system.

In description of adsorption isotherms, please clarify what handling steps have been performed with calcite itself.

The calcite power was used as received, weighed into a $500 \mathrm{~mL}$ polypropylene container and homogenised. The slurry was then measured into centrifuge tubes by weight.

The sentence describing the calcite preparation in the manuscript has been clarified to:

"The slurry was then weighed into centrifuge tubes and increasing amounts of alginate stock solution was added" Page 6 Lines 19-20

On page 19, the authors state that polyelectrolyte adsorption to oppositely charged surfaces is a complicated process, citing papers from 90-ies. Since 
then, this process is much better understood. Subsequently, the structure of polyelectrolytes is discussed. This paragraphs can be certainly improved, but bringing the following: internal structure of polyelectrolytes:

PhysChemChemPhys 2006, 8, 5012-5033; ions contents in polyelectrolyte: Maromolecul. 2019, 52, 9149-9159; a better stability of Ca-crosslinked alginates for biological application: J. Mater. Chem. B 2019, 7, 6778-6788.

We have improved the paragraph to include extra elements of polyelectrolyte adsorption as the reviewer recommends. The following has been added:

Entropic effects are also expected to play a major role in the adsorption of oppositely charged polyelectrolyte adsorption through the release of surface bound charge compensating counterions. ${ }^{40}$ Page 20 Lines 3-5

This is a nice study, but it can be better linked with the actual potential application. Dissolving calcium carbonate surfaces is relevant, but the formation of the polysaccharide coatings crosslinked with multiple di-valent atoms (like $\mathrm{Ca}, \mathrm{Mg}$ ) have been shown to be used for biomedicine as injectable materials: Biomed. Mater. 2017, 12, 025015 and Int. J. Biolog.Macromol. 2018, 118, 1257-1266.

We thank the reviewer for highlighting a potential application and a wider audience for this paper. We have included the references in the discussion as follows:

"These results can be used to understand the formation of highly charged polysaccharide coatings and hydrogels in the presence of divalent cations for biodegradable tissue scaffolds or injectable biomaterials. ${ }^{45-47, " ~ P a g e ~} 21$ Lines 6-8

Other changes:

We have updated the graphical abstract to better describe the outcome of the experiment pictorially:

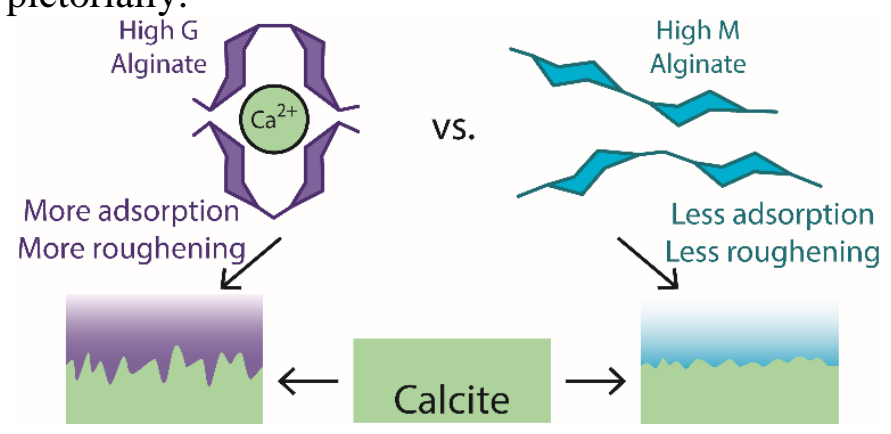


With these changes and revisions, we hope that the paper is now be acceptable for publication in Journal of Colloid and Interface Science.

Yours sincerely,

Kathryn Browning

Assistant Professor 

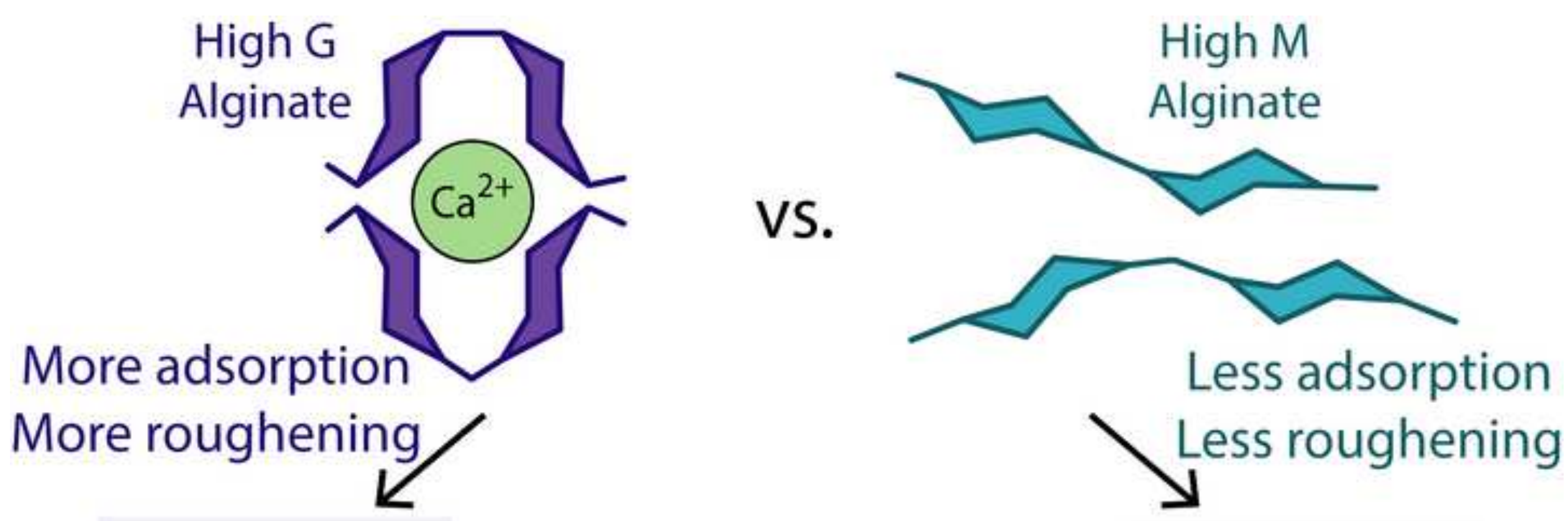

\section{Calcite}

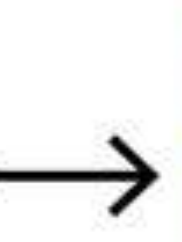




\title{
The effect of alginate composition on adsorption to
}

\section{calcium carbonate surfaces}

\author{
Kathryn Louise Browning ${ }^{a, b^{*}}$, Isabella N Stocker ${ }^{a, c}$, Philipp Gutfreund ${ }^{d}$, Stuart Matthew Clarke ${ }^{a}$ \\ ${ }^{a}$ BP Institute, University of Cambridge, Cambridge, UK \\ ${ }^{b}$ Department of Pharmacy, University of Copenhagen, Copenhagen, Denmark \\ ${ }^{c}$ BP Exploration Operation Company Ltd., Sunbury-on-Thames, UK \\ ${ }^{d}$ Institut Laue-Langevin, Grenoble, France
}

\begin{abstract}
Bacterial anchoring to limestone rocks is thought to occur by selective adsorption of biomolecules found in the extracellular matrix, such as polysaccharides. Here we study the adsorbed structure of a model matrix polysaccharide, sodium alginate, at the calcite/water interface using neutron reflection (NR). Sodium alginate was found to form highly hydrated layers extending up to $350 \AA$ into solution at concentrations up to $2.5 \mathrm{ppm}$ (the inflection point of the adsorption isotherm). The adsorption of alginate was driven by dissolution of the calcite surface through complexation of free calcium ions. This was shown using two alginates with differing ratios of sugar residues. Alginates with a higher proportion of guluronic acid $(\mathrm{G})$ have a higher affinity for calcium ions and were found to cause the surface to dissolve to a greater extent and to adsorb more at the surface when compared to alginates with a higher proportion of
\end{abstract}


mannuronic acid (M). Adding magnesium to the high $\mathrm{G}$ alginate solution reduced dissolution of the surface and the adsorbed amount. In this work, we have shown that polysaccharide adsorption to sparingly soluble calcite interfaces is closely related to polymer conformation and affinity for free calcium ions in solution.

KEYWORDS

- Calcium Carbonate

- Calcite

- Biomineralization

- Alginate

- Polysaccharides

3 Most of the Earth's calcite $\left(\mathrm{CaCO}_{3}\right)$ is of biogenic origin from carbonaceous marine organism

4 sedimentation. Calcium carbonate biomineralisation provides structure throughout Nature from

5 avian eggshells to marine molluscs and coccoliths. ${ }^{1,2}$ The fine control of crystal morphology,

6 phase and grain size is moderated through the production of various biomolecules, which also

7 affect the mechanical properties. ${ }^{2,3}$ The precise mechanism by which these molecules interact

8 with the crystallizing medium through nucleation and growth is an area of current interest in

9 several areas, including amorphous calcium carbonate precursor phases (ACC). ${ }^{3-9}$

10 Calcium carbonate can be precipitated in several different polymorphs of varying stability. The 11 most stable polymorph under ambient conditions is calcite; it can form large defect-free crystals,

12 making it suitable as the focus of this experimental study. It is sparingly soluble in water with a 13 solubility product at room temperature of $\mathrm{K}_{\mathrm{sp}}=3.7 \times 10^{-9} \mathrm{~mol} \mathrm{dm}^{-3}{ }^{10}$ This dissolution 14 complicates the analysis of adsorption to calcite surfaces as acidic conditions can lead to a highly 
1 dynamic interface. The dissolution or precipitation of calcite is closely linked with other aqueous

2 equilibria that determine the extent of dissolution of the surface. ${ }^{11}$

3 The driving force for adsorption of polyanionic polysaccharides is expected to be the affinity of

4 the charged carboxylate groups for calcium on the positively charged calcite surface. Calcium

5 cations released from the calcite surface are sequestered to the sugar forming a complex. This

6 process in turn removes calcium from the solution shifting the equilibrium such that more

7 calcium carbonate solid is dissolved. Polyanionic polysaccharides have been shown to affect the

8 crystal growth structure of calcium carbonate by interacting with the mineral surface suggesting

9 specific interactions with the calcite surface. ${ }^{12}$ Furthermore, negatively charged sugars secreted

10 by bacteria into the extracellular matrix may aid anchoring of the cell to calcitic limestone rocks

11 in marine environments. ${ }^{13,14}$

12 Sodium alginate has been chosen for this study as a model polysaccharide due to its well13 understood structural characteristics and calcium binding properties, allowing the interplay 14 between complex-mediated surface dissolution and polymer adsorption to be investigated. ${ }^{15}$ 15 Alginates are a major structural component of marine algae and secreted by some bacteria, most 16 notably Pseudomonas aeruginosa and Azotobacter vinelandii. ${ }^{16}$ As schematically illustrated in 17 Figure 1, sodium alginate is a copolymer of two epimers, mannuronic acid (M) and guluronic 18 acid (G), which differ only by the conformation of the 1,4 glycosidic link. The two sugar 19 residues can be found either as homopolymeric blocks of each sugar or as alternating MG 20 sequences. ${ }^{17}$ The primary structure of alginate affects the macromolecular properties greatly. GG 21 blocks are rigid as the axial linkage decreases movement and provides a binding site for divalent 22 cations. Conversely, MM blocks are joined via an equatorial glycosidic linkage are therefore 


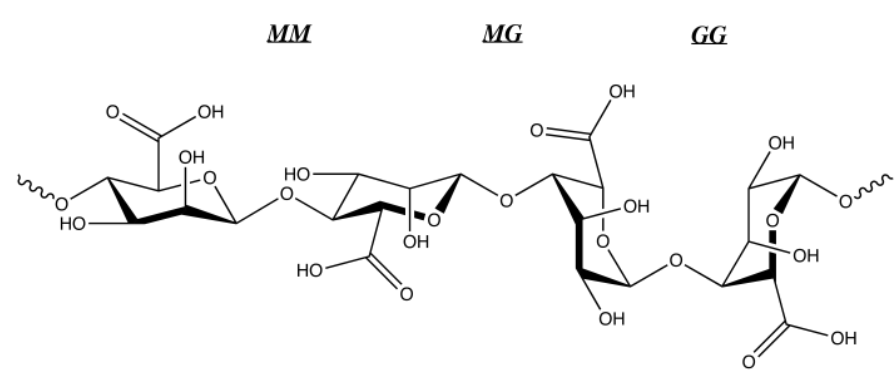

4 Figure 1: Molecular structure of the alginic acid showing the various links between the two epimers, MM, MG and 5

6 Two gram negative, alginate producing, bacteria, Pseudomonas aeruginosa and Azotobacter

7 vinelandii, secrete alginates with different compositions, macromolecular properties and

8 functions. $P$. aeruginosa secretes alginate as a protective envelope and adhesive molecule in

9 biofilm formation in the lung, these alginates have little to no G blocks. ${ }^{16}$ Conversely, $A$. 10 vinelandii, a soil bacterium that forms exopolysaccharide cysts in soil to protect from mechanical 11 stress and desiccation during dormancy, produces alginates with high ratios of GG blocks and 12 alternating sequences in the outer protective layer. ${ }^{16}$

13 The more rigid GG sections provide well-defined chelation sites, which leads to gelation on 14 addition of calcium. The more flexible MM and MG blocks deform to allow adjacent GG 15 disaccharide units to line up form a chelating cage composed of four G saccharide units. ${ }^{18}$ This 16 ability to co-ordinate is strongly linked to conformational structure, alginates with a higher 17 proportion of $\mathrm{G}$ (and $\mathrm{G}$ blocks) gel at lower concentrations of calcium ions and form stronger 18 and more brittle gels. ${ }^{19,20}$ Grant et al. defined this guluronate-Ca interaction the 'egg-box model' 19 due to the alignment of guluronate chains along a plane of calcium ions. ${ }^{17,21}$ In contrast to 
1 calcium, the binding of magnesium with alginate molecules is reported to be a non-specific

2 interaction. ${ }^{22,23}$ Magnesium alginate is soluble and does not strongly interact with any specific

3 binding sites. ${ }^{23,24}$

4 In this study we have used neutron reflection and bulk solution depletion isotherms to compare 5 the adsorption of two different sodium alginate samples with either a low (MVM) or high

6 (MVG) content of guluronate residues to calcium carbonate surfaces. Considering the higher

7 affinity of guluronate residues to calcium ions in solution, the two alginates are expected to show

8 very different surface adsorption profiles in terms of both adsorbed amount and structure.

9 Neutron reflectivity allows the measurement of complex adsorbed structures at the solid/liquid 10 interface, something which is challenging using other techniques. The study of the solid/liquid 11 interface using neutron reflection has been reasonably limited to a small number of single crystal 12 interfaces, mainly silicon, quartz and sapphire. ${ }^{25}$ Recently the number of mineral surfaces used in 13 reflection experiments has widened to include calcite, however, previous work has focused on 14 the adsorption of industrial chemicals and surfactants at the calcite/liquid interface. ${ }^{26-28}$ Here we 15 aim to investigate the adsorption of biopolymers to calcite surfaces in aqueous environments to 16 show how polymer conformation and calcium ion dissolution from the calcite surface can affect 17 adsorbed amount and structure at the interface.

\section{EXPERIMENTAL}

\section{MATERIALS}

20 All experiments were carried out using two ultrapure and well-characterised alginates (Pronova 21 UP Test kit) obtained from Novamatrix. The two alginates tested were of medium viscosity $22(>200 \mathrm{mPa}$ s) and high molecular weight $(>200 \mathrm{kDa})$ and differ by the ratio of the two sugar 
1 epimers. The high guluronate sample (Medium Viscosity Guluronate, MVG) was reported to

2 have a viscosity of $263 \mathrm{mPa}$ s and contain $69 \%$ guluronate residues. The high mannuronate

3 sample (Medium Viscosity Mannuronate, MVM) was found to have a higher viscosity (553

$4 \mathrm{mPa}$ s) with a mannuronic acid content of $54 \%$. All values quoted here were obtained from the

5 manufacturers certificate of analysis of the batch used.

6 Calcium carbonate powder ( $\geq 99 \%)$ used for adsorption isotherms and to saturate water for NR 7 experiments was purchased from Sigma Aldrich. Calcite crystals used in neutron reflection 8 experiments were optically clear Iceland Spar crystals obtained from P\&E Export Ltd, Brazil.

9 The large rhombohedral crystals were cut to a cuboid shape (40 $\times 55 \times 15 \mathrm{~mm})$ and polished to a 10 low roughness by Crystran, Poole, UK. The surface for reflectivity was the most stable $\{10 \overline{1} 4\}$ 11 face, the crystallographic plane found at the surface of the natural rhomb. Attempts were made to 12 cleave the surface rather than polish, however, it was not possible to obtain an area large enough 13 for reflectivity studies (roughly $20 \mathrm{~cm}^{2}$ ) without introducing large steps, causing the cells to leak. 14 The roughness of the polished crystals was assessed by X-ray reflectivity on a Rigaku SmartLab 15 X-ray diffractometer (ISIS, Rutherford Appleton Laboratory, Didcot, UK). This measurement 16 gave an approximate indication of the quality of the surface (data shown in supporting 17 information, Figure S1). Crystals, which had an X-ray roughness less than $15 \AA$, were then used 18 in neutron reflectivity experiments.

\section{ADSORPTION ISOTHERMS}

20 Isotherm measurements were carried out using a solution depletion batch method. $2 \mathrm{~g}$ of calcium 21 carbonate powder was homogenised with $498 \mathrm{~g}$ ultrapure water using a Silverson L4R shear 22 mixer for 10 minutes. The slurry was then weighed into centrifuge tubes and increasing amounts 
1 of alginate stock solution was added. The samples were agitated overnight and centrifuged at

$215,000 \mathrm{G}$ for 20 minutes. The supernatant was removed and filtered through a $0.45 \mu \mathrm{m}$

3 polyethersulfone syringe filter (QMX, UK). The Total Organic Carbon content of the supernatant

4 was measured using a GE InnovOx TOC Analyser. During analysis, the supernatant was

5 acidified and purged with nitrogen to remove traces of inorganic carbonates. The concentration

6 of non-purgeable carbon remaining in the supernatant was then used to calculate the adsorbed

7 amount of alginate.

\section{NEUTRON REFLECTIVITY}

9 The experiment is performed by illuminating a large flat crystal with a collimated beam of 10 neutrons, which reflect and/or refract at the solid/liquid interface. The intensity of the reflected 11 beam is then measured as a function of wavelength and reflected angle. In this experiment, the 12 D17 reflectometer at the Institut Laue-Langevin, France, ${ }^{29}$ was used in the time-of flight (TOF) 13 mode where a polychromatic beam of neutrons is directed at the sample and the wavelength 14 determined by the time taken for neutrons to reach the detector from the source. The determined 15 wavelength values are converted to a momentum transfer vector, Q, calculated from equation 1.

$$
Q=\frac{4 \pi \sin \theta}{\lambda}
$$

16 The use of the TOF method on D17 allows the entire scattering range of interest of the

17 reflectivity curve to be measured using only two incident angles, $0.6^{\circ}$ and $2.0^{\circ}$, to cover the $\mathrm{Q}$

18 range of interest (0.006-0.2 $\left.\AA^{-1}\right)$. To ensure no contribution from the edges of the sample, a

19 constant beam footprint of $30 \times 45 \mathrm{~mm}^{2}$ was maintained on the sample surface. The dQ/Q

20 resolution varied between $1.5-10 \%$ over the Q range measured, during data fitting a value of $4 \%$

21 resolution was used. The data reduction was performed using the COSMOS software. ${ }^{30}$ 
1 The calcite crystals were cleaned by UV-Ozone treatment (BioForce Nano Procleaner). After

2 irradiation, a small drop of filtered calcium carbonate saturated water was placed on the surface

3 to assess wettability. If the droplet spread the crystal was considered clean, placed immediately

4 against a Teflon trough and sealed in a neutron reflectivity cell (details of cell reflection sample

5 cell are given in Stocker et. $a .^{26}{ }^{26}$. Sample changes were carried out by draining the sample cell

6 by pipette ( $3 \mathrm{~mL}$ cell volume) and refilling in-situ with the required solution, this process was

7 repeated three times and the cell sealed with Teflon plugs.

\section{ANALYSIS OF REFLECTIVITY DATA}

9 The shape of the reflectivity curve at a single interface is determined by the surface roughness

10 and the change in neutron refractive index upon moving from one medium to the next through

11 the surface. Neutron reflection theory is outlined elsewhere. ${ }^{31}$ A particularly powerful aspect of

12 neutron reflection is the seemingly random nature of neutron scattering lengths across the

13 periodic table and between isotopes. The scattering length density (SLD) of a material is

14 calculated using equation 2 where $\mathrm{N}$ is the number density of atoms in a material and $b_{i}$ is the

15 scattering length of each nucleus.

$$
\rho=\sum N b_{i}
$$

16 The isotope effect is most clearly seen by the very different SLDs of $\mathrm{H}_{2} \mathrm{O}$ and $\mathrm{D}_{2} \mathrm{O},-0.56 \times 10^{-}$

$17{ }^{6} \AA^{-2}$ and $6.35 \times 10^{-6} \AA^{-2}$, respectively. Using isotopic substitution it is possible to study different

18 reflectivity profiles in the same chemical environment. In this work, we have measured

19 reflectivity profiles of the calcite/alginate solution in $\mathrm{H}_{2} \mathrm{O}, \mathrm{D}_{2} \mathrm{O}$, and a mixture of the two to form

20 a solution that has the same scattering length density of the calcite crystal $\left(4.69 \times 10^{-6} \AA^{-2}\right)$. This

21 combination of solution contrasts is important to constrain the structural model. By using a 
1 solution with the same SLD as the calcite, a reflected signal is only seen from the adsorbed

2 alginate (alginate $\mathrm{SLD}=2.6 \times 10^{-6} \AA^{-2}$, calculated from the expected molecular formula and

3 specific gravity).

4 The measured reflectivity profile is then analysed by comparison of the experimental data with a

5 model structure. The general approach is to constrain the structural model as much as possible to

6 fit the data. If a single layer is found not be sufficient to fit the experimental data, adsorbed

7 layers can be broken into several smaller blocks/layers to describe adsorbed structures in more

8 detail. In some cases a mathematical description of the SLD profile is appropriate, such as

9 exponential or Gaussian. ${ }^{32}$ In all of these cases, the total reflected intensity from adsorbed layers

10 is calculated using the matrix method developed by Abeles and used in reflectivity fitting

11 programs such as RasCAL. ${ }^{33}$

12 The polymer segment density distribution normal to the surface was modelled in several ways, 13 such as discrete layers, exponential decrease from the surface, or a Gaussian distribution. The 14 best fit to the data in all cases was found using the Gaussian distribution model. The SLD profile 15 through the interface was modelled by dividing a $300 \AA$ region into $10 \AA$ sections with an 16 interlayer roughness fixed to $5 \AA$ to smooth out each interface. The volume fraction of alginate 17 was then calculated in each section and converted to an SLD by assuming the rest of the layer 18 was filled with the subphase water. In all adsorbed alginate datasets it was observed that the 19 volume fraction of alginate had reached background well before the model cut off at $300 \AA$ 20 except for the $2.5 \mathrm{ppm}$ MVG where the model had to be extended to $350 \AA$ to reach background. 21 Using the modelled volume fraction distribution, an adsorbed amount was obtained from the area 22 under the Gaussian polymer segment density distribution curve. Although it was possible to fit a 23 small variation in the Gaussian profile, in all cases the distribution was found to conserve the 
1 area under the curve, within error, providing a good test of the robustness of the values for

2 adsorbed amount. Errors were calculated using the bootstrap error analysis in the RasCAL

3 program, where random parameter values are generated and a fit performed 100 times to

4 generate confidence intervals. The parameter errors were then used to calculate the error in

5 adsorbed amount, assuming the maximum and minimum possible values. The SLDs of substrate,

6 subphase, and adsorbate were fixed, where possible, according to the literature values (Table

7 S1). During the experiment it was noted that there was incomplete exchange of the liquids within

8 the cells as the SLD of the $\mathrm{H}_{2} \mathrm{O}$ subphase could not be fitted to the literature value, but rather a

9 mixture of $\mathrm{H}_{2} \mathrm{O}$ containing some $\mathrm{D}_{2} \mathrm{O}$, only when the liquid in the cell was exchanged from $\mathrm{D}_{2} \mathrm{O}$

10 to $\mathrm{H}_{2} \mathrm{O}$ in situ (despite repeated exchanges). This may be due to insufficient mixing of the two

11 liquids due to the density difference in the cell and the high contact angle between the water and 12 the hydrophobic surface of the Teflon trough.

\section{RESULTS}

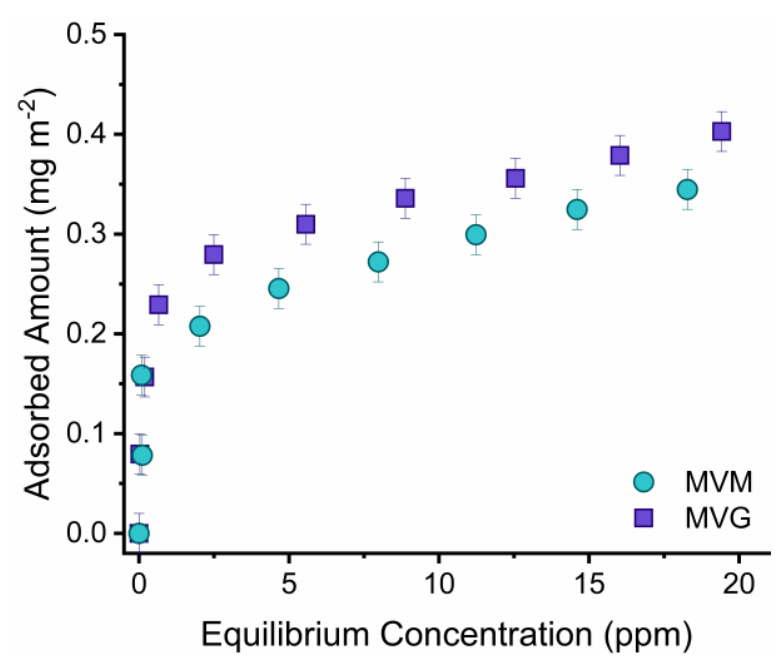

15 Figure 2: Isotherm data of sodium alginate adsorption to calcite powder in water as measured by total organic 16 carbon analysis (TOC). MVM alginate is shown as green circles and MVG as purple squares. 
1 Figure 2 presents bulk solution depletion isotherms for the adsorption of MVM (green circles)

2 and MVG (purple squares) to calcium carbonate powder. It can be seen that there is a small

3 difference between the two alginate solutions with MVG adsorbing more to the surface than

4 MVM. At low concentrations, all alginate is adsorbed as seen from a steep initial increase in

5 adsorbed amount before the turning point of the isotherm at an equilibrium concentrations of

6 roughly $2.5 \mathrm{ppm}$. At higher concentrations, the slope becomes shallower but not flat suggesting

7 that the adsorption does not form a monolayer at the surface. There may be some precipitation of

8 the alginate at higher concentrations as the calcium is dissolved into solution forming insoluble

9 calcium alginate. The interaction between the calcium carbonate surface and alginate is observed

10 to be weak due to the low adsorbed amount at equilibrium. This effect could be accentuated by

11 the sample preparation for TOC analysis. In order to remove calcium carbonate powder from the

12 supernatant, the samples are centrifuged at $15,000 \mathrm{G}$ for 20 minutes which is likely to shear off

13 any loosely bound alginate from the surface leaving only the tightly bound molecules that are

14 effectively irreversibly adsorbed by attachment at multiple points.

\section{NEUTRON REFLECTION}

16 Each calcite crystal was first measured in three saturated calcium carbonate water contrasts, $17 \mathrm{D}_{2} \mathrm{O}, \mathrm{H}_{2} \mathrm{O}$, and water contrast matched to calcite $\left(\mathrm{CMC}=4.69 \times 10^{-6} \AA^{-2}\right)$. A representative 18 dataset is shown in the supporting information (Figure S2). Previous experiments have shown 19 that the surface roughness of calcite does not increase over time in the presence of water 20 saturated with calcium carbonate powder. ${ }^{27}$ The surface cleanliness was confirmed by the 21 absence of any reflected signal above the background level in the CMC contrast (not shown).

22 Measuring the reflectivity in contrast matched water is especially useful due to the high 23 sensitivity to adsorbed layers at the surface. Unlike silicon crystals, which always have a surface 
1 oxide layer and always show a signal in contrast matched water, if the surface of calcite is

2 completely clean there will be no signal recorded. The two $\left(\mathrm{D}_{2} \mathrm{O}\right.$ and $\left.\mathrm{H}_{2} \mathrm{O}\right)$ data sets were fitted

3 simultaneously using only two fitting variables, surface roughness and $\mathrm{H}_{2} \mathrm{O}$ contrast. All bare

4 calcite crystals for the study were successfully fitted to a single interface model and the surface

5 roughness varied from $8.5 \pm 0.6 \AA$ to $9.4 \pm 0.3 \AA$.

6 Before adsorption measurements using neutron reflection it is important to completely 7 characterise the surface that the adsorbate will bind to. Unlike many other surfaces used in 8 reflection the calcite surface can be dynamic and of biogenic origin. Measurements of the bare 9 surface are therefore useful to assess the cleanliness of the substrate and provide an initial 10 roughness characterisation. When calcite is cleaved or polished, high-energy bonding sites are 11 exposed. In air, these sites are likely to be contaminated with species from the atmosphere, 12 however, this bonding of contaminants is generally weak and upon immersion, water molecules 13 compete, removing the contaminants and hydrating the surface with $\mathrm{pH}$ sensitive groups. ${ }^{11,26,34}$

\section{ALGINATE ADSORPTION}

15 Figure 3 presents experimental neutron reflectivity data of the calcite/water interface in the 16 presence of (a) $2.5 \mathrm{ppm}$ MVM and (b) $2.5 \mathrm{ppm}$ MVG alginate in three contrasts, $\mathrm{D}_{2} \mathrm{O}$ (purple 17 squares), $\mathrm{H}_{2} \mathrm{O}$ (green circles), and water contrast matched to calcite (CMC, yellow triangles). 18 Corresponding SLD profiles are provided in the supporting information (Figure S3). Alginate 19 solutions were introduced to the sample cells at concentrations of 0.5 and $1 \mathrm{ppm}$ in $\mathrm{D}_{2} \mathrm{O}$. Three 20 water contrasts were recorded for the highest concentration, $2.5 \mathrm{ppm}$. The concentration of 2.5 21 ppm was chosen to be just above the turning point of the plateau for both MVM and MVG 
1 alginates in solution depletion isotherms (Figure 2). This represents concentration where the

2 surface is expected to be covered but before the onset of multilayer formation or precipitation.
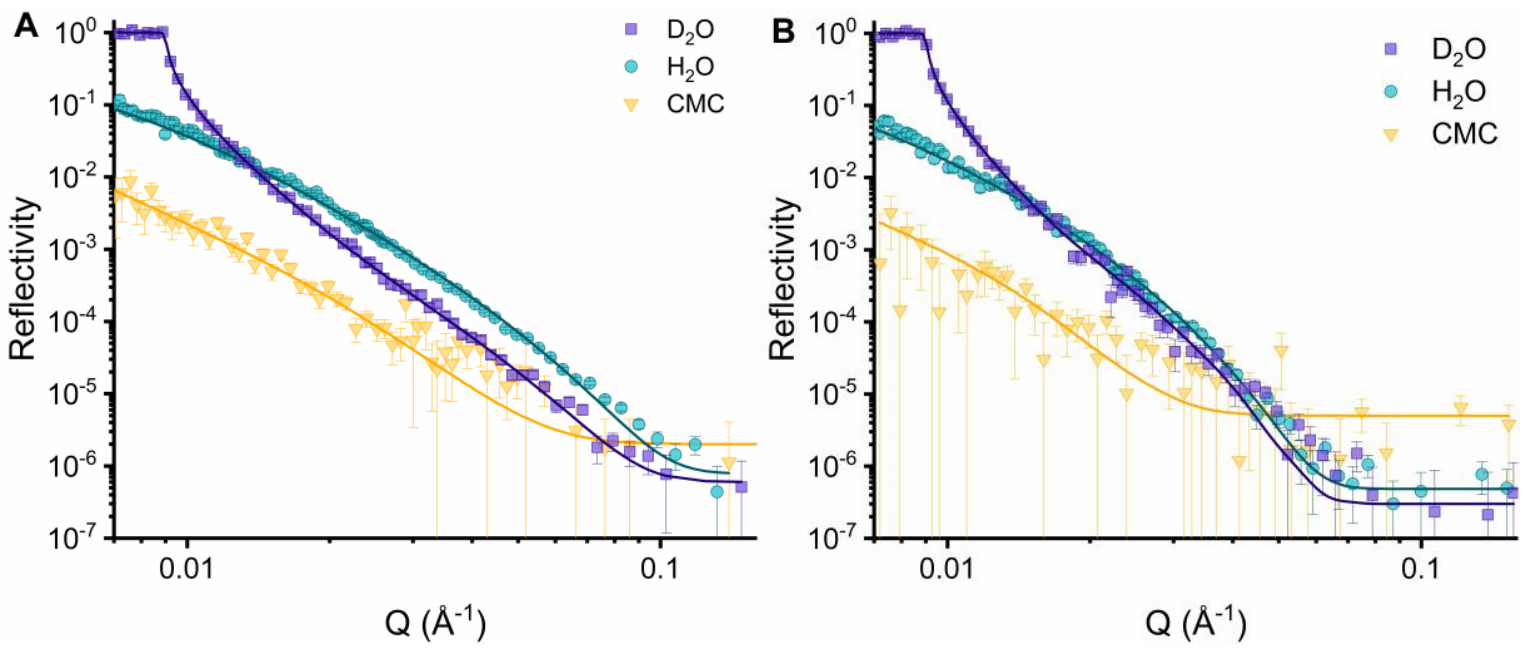

5 Figure 3: Experimental neutron reflectivity data of the calcite/water interface in the presence of A $2.5 \mathrm{ppm}$ MVM

6 and $\mathbf{B} 2.5$ ppm MVG alginate in three contrasts, $\mathrm{D}_{2} \mathrm{O}$ (purple squares), $\mathrm{H}_{2} \mathrm{O}$ (green circles) and water contrast

8 Upon introduction of alginate the intensity of the reflectivity in both the $\mathrm{H}_{2} \mathrm{O}$ and $\mathrm{D}_{2} \mathrm{O}$ contrasts

9 drop, suggesting that the surface is roughening and/or a diffuse layer is adsorbed. A signal is also

10 seen in the contrast matched water indicating an adsorbed layer was present at the surface. This

11 signal in the contrast matched water is purely from any adsorbed material at the interface and

12 therefore has a rather low signal-to-noise ratio and large error bars. The $2.5 \mathrm{ppm}$ MVM data was

13 fitted to a Gaussian layer model with an adsorbed amount of $1.6 \pm 0.4 \mathrm{mg} \mathrm{m}^{2}$ and a surface

14 roughness of $16.1 \pm 0.9 \AA$. The volume fraction of alginate at the surface was found to be 0.098

15 showing that the adsorbed layer is highly hydrated at the interface. The volume fraction

16 decreases away from the surface into solution before reaching zero between 200 and $250 \AA$. As 
1 the concentration of MVM alginate increases, the amount adsorbed at the surface initially

2 increases and begins to level off reaching $1.6 \pm 0.4 \mathrm{mg} \mathrm{m}^{2}$ at $2.5 \mathrm{ppm} \mathrm{MVM}$. The SLD of the

3 subphase in the $\mathrm{H}_{2} \mathrm{O}$ was fitted to be higher $\left(2.28 \pm 0.05 \times 10^{-6} \AA^{-2}\right)$ than the literature value of -

$40.56 \times 10^{-6} \AA^{-2}$, due to incomplete exchange, as discussed above. Table 2 shows the surface

5 roughness and adsorbed amounts obtained from each fit to the Gaussian model described above.

\begin{tabular}{|c|c|c|c|c|c|}
\hline Alginate Used & Parameter & $\begin{array}{c}\text { Bare } \\
\text { surface }\end{array}$ & $\underline{0.5 \mathrm{ppm}}$ & $\underline{1 p p m}$ & $\underline{2.5 \mathrm{ppm}}$ \\
\hline \multirow{2}{*}{ MVM } & Surface Roughness $(\AA)$ & $9.4 \pm 0.3$ & $9.4 \pm 1.1$ & $10.6 \pm 2.0$ & $16.1 \pm 0.9$ \\
\hline & Adsorbed amount ( $\left.\mathrm{mg} \mathrm{m}^{-2}\right)$ & - & $1.0 \pm 0.5$ & $1.4 \pm 0.1$ & $1.6 \pm 0.4$ \\
\hline \multirow{2}{*}{ MVG } & Surface Roughness $(\AA)$ & $8.9 \pm 0.4$ & $12.5 \pm 1.3$ & $18.0 \pm 1.4$ & $34.5 \pm 0.7$ \\
\hline & Adsorbed amount $\left(\mathrm{mg} \mathrm{m}^{-2}\right)$ & - & $1.7 \pm 0.3$ & $2.7 \pm 0.2$ & $2.8 \pm 0.3$ \\
\hline \multirow{2}{*}{$\begin{array}{c}\mathrm{MVG}+12 \mathrm{mM} \\
\mathrm{MgCl}_{2}\end{array}$} & Surface Roughness $(\AA)$ & $8.5 \pm 0.6$ & - & - & $27.3 \pm 0.5$ \\
\hline & Adsorbed amount $\left(\mathrm{mg} \mathrm{m}^{-2}\right)$ & - & - & - & $0.7 \pm 0.3$ \\
\hline
\end{tabular}

Table 2: Values for roughness and adsorbed amount obtained from fits to the data of the adsorption to

the calcite surface of sodium alginate in pure water.

8 Figure $3 \mathrm{~b}$ shows the experimental data measured for $2.5 \mathrm{ppm}$ MVG in all three water contrasts.

9 The data was fitted to a Gaussian layer model, as above, and again found to give good agreement 10 in all datasets. The SLD of the $\mathrm{H}_{2} \mathrm{O}$ contrast was again found to be higher than literature (3.28 \pm $110.07 \times 10^{-6} \AA^{-2}$ ) as for MVM alginate. The polymer distribution was found to extend further into 12 solution compared to MVM, suggesting that the MVG molecule is less attracted to the calcite 13 surface. This may also be related to a greater degree of cross-linking by calcium ions compared 
1 to MVM alginate. ${ }^{17}$ The modelled roughness, $34.5 \pm 0.7 \AA$, is large and the reflected signal

2 (above the critical edge) was much lower than for other measurements and reached background

3 at lower Q. The larger roughness indicates more calcium is released into the solution to achieve

4 equilibrium when compared to MVM alginate. The amount adsorbed with concentration follows

5 a similar profile as the MVM alginate; however, the value at $2.5 \mathrm{ppm}$ is higher $\left(2.8 \pm 0.3 \mathrm{mg} \mathrm{m}{ }^{2}\right)$

6 showing that more alginate is adsorbed when the polymer contains higher ratios of guluronate 7 residues.

\section{HIGH GULUORNATE ALGINATE WITH MAGNESIUM}

9 The reflectivity study of the MVG alginate adsorption to calcite in pure water indicated 10 significant surface roughening, attributed here to sequestration of calcium by the alginate 11 molecule. It is not possible to pre-saturate the water with calcium ions due to the insolubility of 12 calcium alginate and hence transport of calcium alginate to the calcite surface for adsorption 13 would be impossible. By adding $12 \mathrm{mM} \mathrm{MgCl}_{2}$ (same concentration of calcium in saturated $14 \mathrm{CaCO}_{3}$ water) and allowing the system to equilibrate, the magnesium ions bind non-specifically 15 with the alginate, reducing the effective charge of the polymer, making it less likely to be 16 attracted to the calcite surface. ${ }^{23}$ The affinity of magnesium compared to calcium is thought to be 17 similar for $\mathrm{MM}$ and $\mathrm{MG}$ blocks but considerably smaller for GG blocks where specific 18 interactions with calcium prevail. As the alginates used in the study contain a mixture of all 19 blocks, we expect that the number of calcium ions removed from the surface will be lowered by 20 the presence of magnesium and therefore less roughening of the calcite surface upon introduction 21 to the sample cell. Magnesium ions have also been shown to bind to high energy sites on the 22 calcite surface inhibiting dissolution. ${ }^{35}$ 
2 Figure 4: Experimental neutron reflectivity data of the calcite/water interface in the presence of $2.5 \mathrm{ppm}$ MVG pre3 equilibrated with $12 \mathrm{mM} \mathrm{MgCl}_{2}$ in two contrasts, $\mathrm{D}_{2} \mathrm{O}$ (purple squares) and $\mathrm{H}_{2} \mathrm{O}$ (green circles). Calculated fits to

5 Figure 4 shows the fitted reflectivity data upon introduction of $2.5 \mathrm{ppm}$ MVG pre-equilibrated 6 with $12 \mathrm{mM} \mathrm{MgCl}$ in $\mathrm{D}_{2} \mathrm{O}$ (purple circles) and $\mathrm{H}_{2} \mathrm{O}$ (green circles). The corresponding SLD 7 profile is provided in the supporting information (Figure S3). It was not possible to measure the 8 CMC contrast due to time constraints of the experiment. The reflectivity profile shows a weak 9 Kiessig fringe at higher Q suggesting a more defined adsorbed layer. Upon fitting the datasets, 10 the maximum of the Gaussian polymer distribution is found to lie away from the calcite surface 11 (Figure 5a) and the adsorbed amount is lower than for MVG in pure water $(0.7 \pm 0.3$ compared 12 to $2.8 \pm 0.3 \mathrm{mg} \mathrm{m}^{-2}$ ). The surface roughness was also found to be lower $27.3 \pm 0.5 \AA$ compared 13 to $34.5 \pm 0.7 \AA$. The reduction in surface roughness by pre-saturation of the MVG with $12 \mathrm{mM}$ $14 \mathrm{MgCl}_{2}$ was not as pronounced as expected, suggesting that the affinity of MVG alginate for 15 calcium ions is high even if the charge is compensated by other divalent ions. The composition 16 of the alginate (i.e. the proportion and order of $M$ to $G$ residues) plays a greater role in the extent 17 of calcite surface roughening than the availability of divalent ions in the solution. 
A

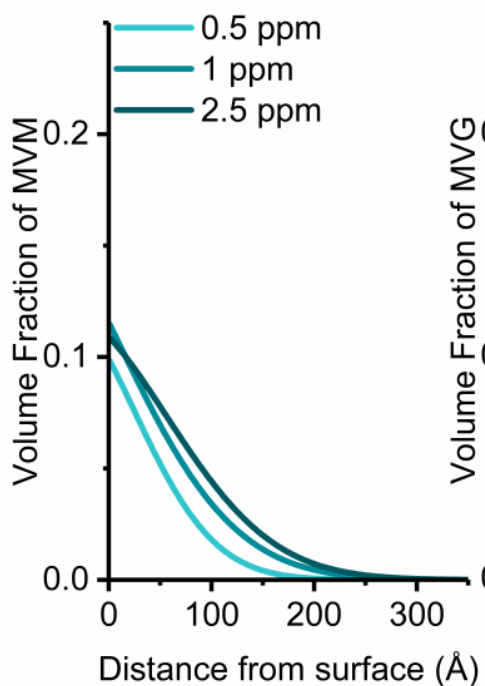

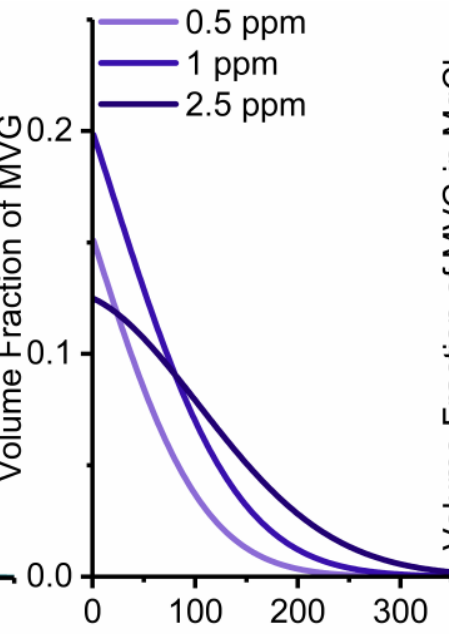

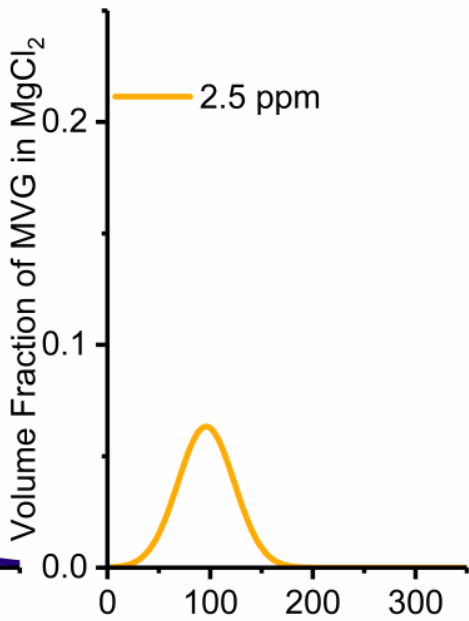

B

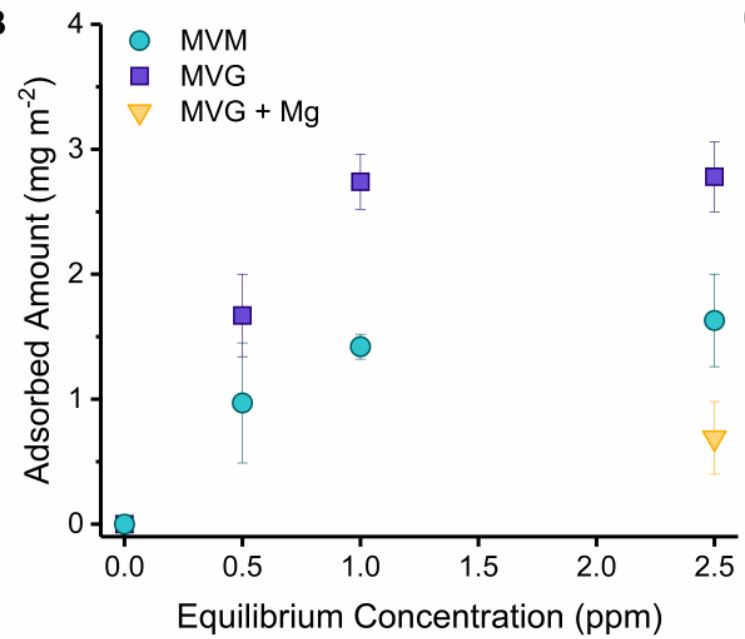

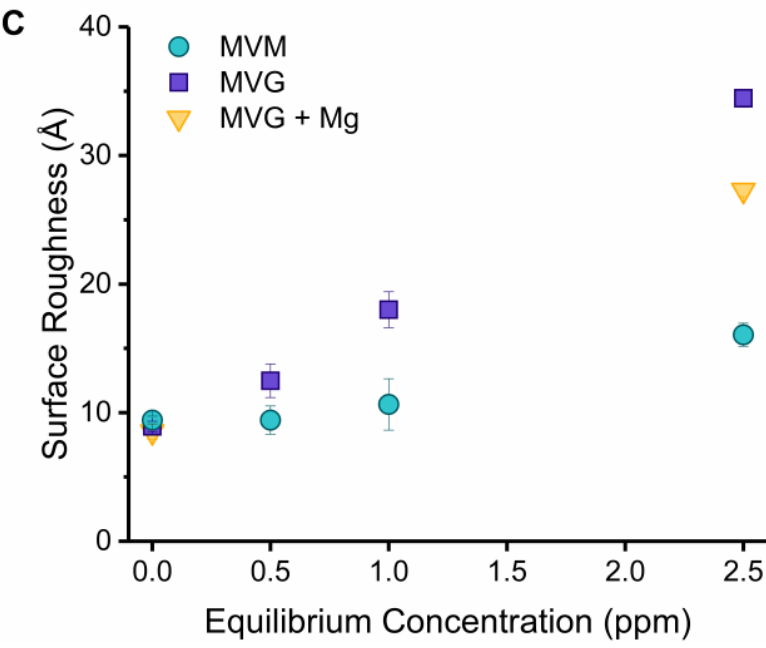


1 The data above shows the pronounced effect of the structural composition of sodium alginate on

2 both the adsorption to and roughening of the surface of calcite crystals. Figure 5 summarizes the

3 differences observed in adsorbed amounts (Fig 5b) and calcite surface roughness (Fig 5c). As

4 described above the adsorbed amount increases from zero but reached a plateau at higher

5 concentrations. The surface roughness increases with concentration, suggesting that the

6 sequestering of calcium ions to the alginate drives the surface dissolution of calcite. In the

7 reflection experiments reported here we must carefully consider the solution and surface

8 behaviour. Sodium alginate in the presence of calcium ions readily converts to calcium alginate,

9 which has a very low solubility. In order to introduce the alginate to the sample cell without

10 precipitation the reflectivity experiments must be run in pure water. However, the introduction of

11 pure water to the calcite surface increases surface dissolution and roughening. ${ }^{26}$ The technique of

12 neutron reflection requires very flat surfaces for a good reflected signal and hence any

13 dissolution should be kept small. However, we also exploit the sensitivity of the reflection to this

14 roughening as an ideal way of probing the surface dissolution. In previous studies, calcite in

15 contact with pure water was found to roughen quickly before plateauing at a roughness $2 \mathrm{~nm}$

16 greater than the original surface..$^{26,36}$

\section{DISCUSSION}

18 This work is able to report on significant differences in the adsorption and surface roughening

19 between the two investigated alginates: the alginate with the higher proportion of guluronate 20 residues (MVG) is found increase calcite dissolution and shows a higher adsorption to the calcite 21 surface compared to the alginate with a lower proportion of guluronate (MVM). As discussed 22 above, alginate in the presence of calcium is reported to crosslink preferentially between GG 23 units causing gelation and insolubility known as the 'egg-box' model. ${ }^{17,21}$ Therefore, the higher 
2 However, the difference in M:G ratios between the two alginates is not large (46 \% vs. $69 \%$

3 guluronate residues) compared to the observed effects. The overall composition of the alginate

4 does not tell us the sequence of sugar residues, which can consist of three different repeat unit

5 sections, GG blocks, MM blocks or alternating MG blocks. The two alginates used in this study

6 have not been tested for the proportion of each of these pair wise sections. Therefore, the MVG

7 alginate may have a significantly higher proportion of the $G$ residues in blocks of pure

8 guluronate (i.e. GG) rather than in alternating MG sections. GG blocks are the most effective at

9 crosslinking to form the 'egg box' structure that causes the molecule to become insoluble and

10 inflexible. Furthermore, higher proportions of $\mathrm{G}$ blocks may favour polymer-polymer 11 conformations rather than polymer-surface interactions and a more extended polymer 12 conformation reaching out from the surface as we see for the $2.5 \mathrm{ppm} \mathrm{MVG} \mathrm{alginate} \mathrm{where} \mathrm{the}$ 13 polymer extends much farther out into solution as compared to MVM.

14 Addition of magnesium ions to the alginate solutions before introduction to the cell was found to 15 reduce the alginate binding and surface roughness. This effect is probably due to lower effective 16 charge of the alginate molecule by non-specific interactions with magnesium ions and lower 17 binding of calcium leading to less ion removal from the calcite surface. ${ }^{22}$. In addition, the pre18 equilibrated alginate formed a different adsorption profile with maximum adsorbed amount lying 19 away from the surface as compared to that obtained from alginate adsorbed from pure water 20 solutions where the maximum was found to lie at the surface of the calcite.

21 Polyelectrolyte adsorption to oppositely charged surfaces in low ionic strength solutions is 22 complex and depends on a number of factors, including effective charge of the molecule due to 23 specific ion binding, ionic strength, and surface charge. ${ }^{37,38}$ At the interface, polyelectrolytes can 
1 form trains, loops, and tails, in differing ratios depending on the system of study. For lower

2 polyelectrolyte charge densities, as would be expected for calcium saturated alginate in low salt

3 conditions, loop and tail adsorption is favoured. ${ }^{37,39}$ Entropic effects are also expected to play a

4 major role in the adsorption of oppositely charged polyelectrolyte adsorption through the release

5 of surface bound charge compensating counterions. ${ }^{40}$ Also, in low ionic strength conditions the

6 electrical double layer would extend far enough to trap molecules electrostatically.

7 There is a large body of work attempting to describe the interactions between alginate and

8 calcium and its effect on calcium carbonate biomineralisation and dissolution. Experimental and

9 theoretical treatments of the 'egg box' model have shown the process to occur via three stages

10 during which mono then bi-dentate binding is seen before larger aggregations form, linked by

11 calcium ions. ${ }^{15,41}$ Borgogna et. al. reported the specific binding of calcium ions to alginate occurs

12 even at low concentration of calcium equilibrated with water. ${ }^{42}$ The binding proceeds via a tilted 13 egg-box model to minimise the repulsive interactions of the negative carboxylic acid groups.

14 Experiments at the interface are more scarce, Perry et. al. studied the dissolution behaviour of 15 calcite in the presence of alginate and reported that etch pits on the surface were lengthened 16 along the obtuse angle of the rhombohedral pit due to bidentate binding of the high energy 17 calcium at the edge of the pit to a GG dimer. ${ }^{43,44}$ In these experiments, the proportion of 18 guluronate residues is suggested to be the key to the increased interactions with calcium ions.

19 The present work agrees well with the solution and adsorption data from previous studies where 20 the high guluronate alginate (MVG) both adsorbs more to the calcite surface and dissolves the 21 surface to a greater extent than the same concentration of alginate with a lower guluronate 22 content (MVM). By studying this complex system using neutron reflection we were able to study 23 not only the adsorbed amount but also how the alginate adsorbed structure is affected by sugar 
1 chain composition and the addition of magnesium. We find that the adsorbed amount is greatly

2 reduced when studying bulk isotherms that have been centrifuged, indicating that $90 \%$ of the

3 adsorbed polymer in the static system is only weakly attached to the surface. We also find that

4 higher concentrations of MVG, with and without magnesium ions, extend further out into

5 solution compared to low concentrations and low guluronate alginates suggesting more loop and

6 tail formation and less affinity for the calcite surface. These results can be used to understand the

7 formation of highly charged polysaccharide coatings and hydrogels in the presence of divalent

8 cations for biodegradable tissue scaffolds or injectable biomaterials. ${ }^{45-47}$ Future studies in marine-

9 like salt conditions as well as more complex extracellular matrix polysaccharides would build on

10 this knowledge to understand how bacterial anchoring occurs to limestone rocks and soils.

\section{CONCLUSION}

12 Neutron reflectivity was able to demonstrate processes occurring during adsorption of alginate to 13 calcite surfaces of interest to studies of bacterial anchoring to limestone rocks and 14 biomineralisation. The system is extremely complex in terms of adsorption, solution chemistry 15 and ion complexation. However, by careful control of the solution composition we are able to 16 identify that these polymers are observed to form thick, highly hydrated layers at the surface. 17 The dissolution of the calcite crystal due to polymer complexation was significant and was 18 followed on an Ångström scale without perturbing or removing the adsorbed molecules. The 19 conformation of the 1,4- $\alpha$ linkage of the polysaccharide was found to alter the adsorbed amount 20 and structure of the molecule at the interface. Alginate molecules containing high proportions of 21 guluronate sugar residues adsorbed more and removed more calcium ions from the calcite 22 surface when compared to alginate with a lower proportion of guluronate. This work shows the 
1 importance of polymer conformation and ion affinity on adsorption to dynamic dissolving calcite 2 interfaces.

4 AUTHOR INFORMATION

5 Corresponding Author

6 * Corresponding author. E-mail address: kathryn.browning@sund.ku.dk Tel No:+45 42494825

7 Address: Department of Pharmacy, University of Copenhagen, Universitetsparken 2,

8 Copenhagen 2100, Denmark

\section{$9 \quad$ Author Contributions}

10 KLB, INS, and SMC designed the study. All authors were involved in performing the 11 experiments and in the interpretation of the experimental results. The manuscript was written 12 through contributions of all authors who have approved the final version of the manuscript.

\section{ACKNOWLEDGMENTS}

14 We acknowledge the Partnership for Soft Condensed Matter (PSCM) for the use of the 15 UV/ozone cleaner and the laboratory. We thank the Materials Characterisation Lab at the ISIS 16 Neutron and Muon Source, UK, for use of the x-ray reflectometer and Liv Sofia Elinor 17 Damgaard for help with the XRR data. We thank the ILL for the beam time to study this system 18 (experiment number: 9-10-1140). Martin Malmsten is gratefully acknowledged for helpful 19 discussions during the manuscript preparation. We would like to thank BP Plc. (KLB and INS) 20 and Leo Foundation (Grant No. 2016-11-01, KLB) for funding.

\section{REFERENCES}

22 (1) Hernández-Hernández, A.; Vidal, M. L.; Gómez-Morales, J.; Rodríguez-Navarro, A. B.; 
Labas, V.; Gautron, J.; Nys, Y.; García Ruiz, J. M. Influence of Eggshell Matrix Proteins on the Precipitation of Calcium Carbonate (CaCO3). J. Cryst. Growth 2008, 310 (7-9), 1754-1759. https://doi.org/10.1016/j.jcrysgro.2007.11.170.

(2) Meldrum, F. C. Calcium Carbonate in Biomineralisation and Biomimetic Chemistry. Int.

Mater. Rev. 2003, 48 (3), 187-224. https://doi.org/10.1179/095066003225005836.

(3) Mann, S. The Chemistry of Form. Angew. Chemie 2000, 39 (19), 3392-3406. https://doi.org/10.1002/1521-3773(20001002)39:19<3392::aid-anie3392>3.0.co;2-m.

(4) Addadi, L.; Raz, S.; Weiner, S. Taking Advantage of Disorder: Amorphous Calcium Carbonate and Its Roles in Biomineralization. Adv. Mater. 2003, 15 (12), 959-970. https://doi.org/10.1002/adma.200300381.

(5) Wolf, S. E.; Lieberwirth, I.; Natalio, F.; Bardeau, J. F.; Delorme, N.; Emmerling, F.; Barrea, R.; Kappl, M.; Marin, F. Merging Models of Biomineralisation with Concepts of Nonclassical Crystallisation: Is a Liquid Amorphous Precursor Involved in the Formation of the Prismatic Layer of the Mediterranean Fan Mussel Pinna Nobilis? Faraday Discuss. 2012, 159 (0), 433-448. https://doi.org/10.1039/c2fd20045g.

(6) Xu, A. W.; Ma, Y.; Cölfen, H. Biomimetic Mineralization. J. Mater. Chem. 2007, 17 (5), 415-449. https://doi.org/10.1039/b611918m.

(7) Arias, J. L.; Fernández, M. S. Polysaccharides and Proteoglycans in Calcium CarbonateBased Biomineralization. Chem. Rev. 2008, $108 \quad$ (11), 4475-4482. https://doi.org/10.1021/cr078269p.

(8) Yang, M.; Stipp, S. L. S.; Harding, J. Biological Control on Calcite Crystallization by Polysaccharides. Cryst. Growth Des. 2008, $8 \quad$ (11), 4066-4074. https://doi.org/10.1021/cg800508t. 
1 (9) Meldrum, F. C.; Sear, R. P. Now You See Them. Science (80-. ). 2008, 322 (5909), 18021803. https://doi.org/10.1126/science.1167221.

(10) Haynes, W. M. CRC Handbook of Chemistry and Physics: A Ready-Reference Book of Chemical and Physical Data; CRC Press, 2011.

(11) Stumm, W.; Morgan, J. J. Aquatic Chemistry: An Introduction Emphasizing Chemical Equilibria in Natural Waters; Wiley, 1981.

(12) Butler, M. F.; Glaser, N.; Weaver, A. C.; Kirkland, M.; Heppenstall-Butler, M. Calcium Carbonate Crystallization in the Presence of Biopolymers. Cryst. Growth Des. 2006, 6 (3), 781-794. https://doi.org/10.1021/cg050436w.

(13) Vu, B.; Chen, M.; Crawford, R.; Ivanova, E. Bacterial Extracellular Polysaccharides Involved in Biofilm Formation. Molecules 2009, 14 (7), 2535-2554. https://doi.org/10.3390/molecules14072535.

(14) Decho, A. W. Overview of Biopolymer-Induced Mineralization: What Goes on in $\begin{array}{llllll}\text { Biofilms? } & \text { Ecol. } & \text { Eng. } & \mathbf{2 0 1 0}, & 36 & \text { (2), }\end{array}$ https://doi.org/10.1016/j.ecoleng.2009.01.003.

(15) Fang, Y.; Al-Assaf, S.; Phillips, G. O.; Nishinari, K.; Funami, T.; Williams, P. A.; Li, A. Multiple Steps and Critical Behaviors of the Binding of Calcium to Alginate. J. Phys. Chem. B 2007, 111 (10), 2456-2462. https://doi.org/10.1021/jp0689870.

(16) Sabra, W.; Zeng, A. P.; Deckwer, W. D. Bacterial Alginate: Physiology, Product Quality and Process Aspects. Applied Microbiology and Biotechnology. 2001, pp 315-325. https://doi.org/10.1007/s002530100699.

(17) Smidsrød, O. Molecular Basis for Some Physical Properties of Alginates in the Gel State. Faraday Discuss. Chem. Soc. 1974, 57 (0), 263-274. 
https://doi.org/10.1039/DC9745700263.

2
(18) Donati, I.; Holtan, S.; Mørch, Y. A.; Borgogna, M.; Dentini, M.; Skjåk-Bræk, G. New Hypothesis on the Role of Alternating Sequences in Calcium-Alginate Gels. Biomacromolecules 2005, 6 (2), 1031-1040. https://doi.org/10.1021/bm049306e.

(19) Haug, A.; Myklestad, S.; Larsen, B.; Smidsrød, O.; Eriksson, G.; Blinc, R.; Paušak, S.; Ehrenberg, L.; Dumanović, J. Correlation between Chemical Structure and Physical Properties of Alginates. Acta Chem. Scand. 1967, 21, 768-778. https://doi.org/10.3891/acta.chem.scand.21-0768.

(20) Gacesa, P. Alginates. Carbohydr. Polym. 1988, $8 \quad$ (3), 161-182. https://doi.org/10.1016/0144-8617(88)90001-X.

(21) Grant, G. T.; Morris, E. R.; Rees, D. A.; Smith, P. J. C.; Thom, D. Biological Interactions between Polysaccharides and Divalent Cations: The Egg-Box Model. FEBS Lett. 1973, 32 (1), 195-198. https://doi.org/10.1016/0014-5793(73)80770-7.

(22) Donati, I.; Cesàro, A.; Paoletti, S. Specific Interactions versus Counterion Condensation. 1. Nongelling Ions/Polyuronate Systems. Biomacromolecules 2006, 7 (1), 281-287. https://doi.org/10.1021/bm050646p.

(23) Donati, I.; Asaron, F.; Paoletti, S. Experimental Evidence of Counterion Affinity in Alginates: The Case of Nongelling Ion Mg2+. J. Phys. Chem. B 2009, 113 (39), 1287712886. https://doi.org/10.1021/jp902912m.

(24) Donati, I.; Benegas, J. C.; Cesàro, A.; Paoletti, S. Specific Interactions versus Counterion Condensation. 2. Theoretical Treatment within the Counterion Condensation Theory. Biomacromolecules 2006, 7 (5), 1587-1596. https://doi.org/10.1021/bm050981d.

23 (25) Penfold, J.; Thomas, R. K. The Application of the Specular Reflection of Neutrons to the 
Study of Surfaces and Interfaces. Journal of Physics: Condensed Matter. IOP Publishing 1990, pp 1369-1412. https://doi.org/10.1088/0953-8984/2/6/001.

Stocker, I. N.; Miller, K. L.; Lee, S. Y.; Welbourn, R. J. L.; Mannion, A. R.; Collins, I. R.; Webb, K. J.; Wildes, A.; Kinane, C. J.; Clarke, S. M. Neutron Reflection at the CalciteLiquid Interface; Berlin, Heidelberg, 2012; Vol. 139, pp 91-99. https://doi.org/10.1007/978-3-642-28974-3_16.

(27) N. Stocker, I.; L. Miller, K.; Y. Lee, S.; R. Collins, I.; M. Clarke, S.; J. Webb, K.; J. Kinane, C.; Wildes, A. Adsorption at the Calcite - Liquid Interface with Molecular Precision. In IOR 2011 - 16th European Symposium on Improved Oil Recovery; EAGE Publications BV, 2014. https://doi.org/10.3997/2214-4609.201404793.

(28) Stocker, I. N. I. N.; Miller, K. L. K. L.; Welbourn, R. J. L. R. J. L.; Clarke, S. M. S. M.; Collins, I. R. I. R.; Kinane, C.; Gutfreund, P. Adsorption of Aerosol-OT at the Calcite/Water Interface - Comparison of the Sodium and Calcium Salts. J. Colloid Interface Sci. 2014, 418, 140-146. https://doi.org/10.1016/j.jcis.2013.11.046.

(29) Saerbeck, T.; Cubitt, R.; Wildes, A.; Manzin, G.; Andersen, K. H.; Gutfreund, P. Recent Upgrades of the Neutron Reflectometer D17 at ILL. J. Appl. Crystallogr. 2018, 51 (2), 249-256. https://doi.org/10.1107/S160057671800239X.

(30) Gutfreund, P.; Saerbeck, T.; Gonzalez, M. A.; Pellegrini, E.; Laver, M.; Dewhurst, C.; Cubitt, R. Towards Generalized Data Reduction on a Chopperbased Time-of-Flight Neutron Reflectometer. J. Appl. Crystallogr. 2018, $51 \quad$ (3), 606-615. https://doi.org/10.1107/S160057671800448X.

(31) Sivia, D. S. Elementary Scattering Theory; Oxford University Press, 2013. https://doi.org/10.1093/acprof:oso/9780199228676.001.0001. 
1 (32) Cosgrove, T. Volume-Fraction Profiles of Adsorbed Polymers. J. Chem. Soc. Faraday

Trans. 1990, 86 (9), 1323-1332. https://doi.org/10.1039/FT9908601323.

(33) RasCAL download | SourceForge.net https://sourceforge.net/projects/rscl/ (accessed Feb 20, 2020).

(34) Madsen, L. Calcite: Surface Charge. In Encyclopedia of Surface and Colloid Science, Third Edition; Somasundaran, P., Ed.; Taylor \& Francis Group: New York, 2006; pp 1084-1096. https://doi.org/10.1081/E-ESCS3-120000648.

(35) Compton, R. G.; Brown, C. A. Inhibition of Calcite Dissolution/Precipitation: Mg2+ $\begin{array}{llllllll}\text { Cations. } & \text { J. } & \text { Colloid Interface } & \text { Sci. 1994, } 165 & \text { (2), 445-449. }\end{array}$ https://doi.org/10.1006/jcis.1994.1248.

(36) Bisschop, J.; Dysthe, D. K.; Putnis, C. V.; Jamtveit, B. In Situ AFM Study of the Dissolution and Recrystallization Behaviour of Polished and Stressed Calcite Surfaces. Geochim. Cosmochim. Acta 2006, $70 \quad$ (7), $\quad 1728-1738$. https://doi.org/10.1016/j.gca.2005.12.013.

(37) G. Fleer J.M.H.M. Scheutjens, T. Cosgrove and B. Vincent, M. A. C. S. Polymer at Interfaces; Springer Netherlands, 1998. https://doi.org/https://www.springer.com/gp/book/9780412581601.

(38) Kawaguchi, M.; Takahashi, A. Polymer Adsorption at Solid-Liquid Interfaces. Adv. Colloid Interface Sci. 1992, 37 (3-4), 219-317. https://doi.org/10.1016/00018686(92)80085-C.

(39) Lee, E. M.; Thomas, R. K.; Rennie, A. R. Reflection of Neutrons from a Polymer Layer Adsorbed at the Quartz-Water Interface. EPL 1990, 13 (2), 135-141. https://doi.org/10.1209/0295-5075/13/2/007. 
1 (40) V. Klitzing, R. Internal Structure of Polyelectrolyte Multilayer Assemblies. Physical Chemistry Chemical Physics. The Royal Society of Chemistry November 8, 2006, pp 5012-5033. https://doi.org/10.1039/b607760a.

(41) Braccini, I.; Pérez, S. Molecular Basis of Ca2+-Induced Gelation in Alginates and Pectins: The Egg-Box Model Revisited. Biomacromolecules 2001, 2 (4), 1089-1096. https://doi.org/10.1021/bm010008g.

(42) Borgogna, M.; Skjåk-Bræk, G.; Paoletti, S.; Donati, I. On the Initial Binding of Alginate by Calcium Ions. The Tilted Egg-Box Hypothesis. J. Phys. Chem. B 2013, 117 (24), 7277-7282. https://doi.org/10.1021/jp4030766.

(43) Perry IV, T. D.; Duckworth, O. W.; McNamara, C. J.; Martin, S. T.; Mitchell, R. Effects of the Biologically Produced Polymer Alginic Acid on Macroscopic and Microscopic Calcite Dissolution Rates. Environ. Sci. Technol. 2004, 38 (11), 3040-3046. https://doi.org/10.1021/es035299a.

(44) Perry; Duckworth, O. W.; Kendall, T. A.; Martin, S. T.; Mitchell, R. Chelating Ligand Alters the Microscopic Mechanism of Mineral Dissolution. J. Am. Chem. Soc. 2005, 127 (16), 5744-5745. https://doi.org/10.1021/ja042737k.

Douglas, T. E. L.; Sobczyk, K.; Łapa, A.; Włodarczyk, K.; Brackman, G.; Vidiasheva, I.; Reczyńska, K.; Pietryga, K.; Schaubroeck, D.; Bliznuk, V.; et al. Ca:Mg:Zn:CO 3 and Ca:Mg:CO 3-Tri-and Bi-Elemental Carbonate Microparticles for Novel Injectable SelfGelling Hydrogel-Microparticle Composites for Tissue Regeneration Related Content. Biomed. Mater. 2017, 12 (2), 025015. https://doi.org/10.1088/1748-605X/aa6200.

Ren, B.; Chen, X.; Du, S.; Ma, Y.; Chen, H.; Yuan, G.; Li, J.; Xiong, D.; Tan, H.; Ling, Z.; et al. Injectable Polysaccharide Hydrogel Embedded with Hydroxyapatite and Calcium 


\section{E-MAIL ADDRESSES OF AUTHORS}

15 Kathryn Browning: kathryn.browning@sund.ku.dk

16 Isabella Stocker: isabella.stocker@cantab.net

17 Philipp Gutfreund: gutfreund@ill.fr

18 Stuart Clarke: stuart@bpi.cam.ac.uk https://doi.org/10.1039/c9tb01287g.

VS.

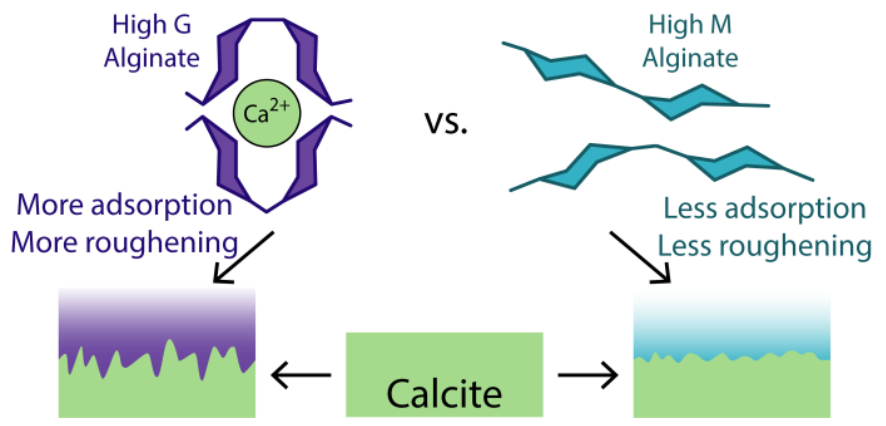

ption

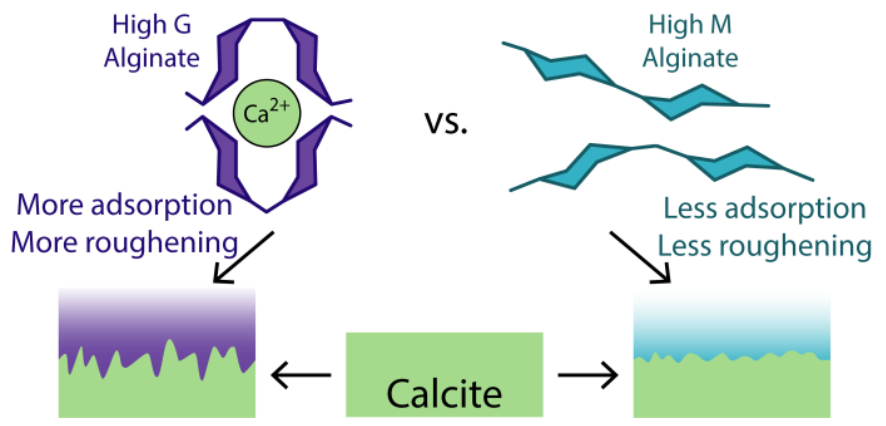

Carbonate for Drug Delivery and Bone Tissue Engineering. Int. J. Biol. Macromol. 2018, 118, 1257-1266. https://doi.org/10.1016/j.ijbiomac.2018.06.200.

(47) Saveleva, M.; Vladescu, A.; Cotrut, C.; Van Der Meeren, L.; Surmeneva, M.; Surmenev, R.; Parakhonskiy, B.; Skirtach, A. G. The Effect of Hybrid Coatings Based on Hydrogel, Biopolymer and Inorganic Components on the Corrosion Behavior of Titanium Bone Implants. J. Mater. Chem. $\quad B \quad$ 2019, $7 \quad$ (43), 6778-6788.

9




\title{
The effect of alginate composition on adsorption to
}

\section{calcium carbonate surfaces}

\author{
Kathryn Louise Browning ${ }^{a, b^{*}}$, Isabella N Stocker ${ }^{a, c}$, Philipp Gutfreund ${ }^{d}$, Stuart Matthew Clarke ${ }^{a}$ \\ ${ }^{a}$ BP Institute, University of Cambridge, Cambridge, $U K$ \\ ${ }^{b}$ Department of Pharmacy, University of Copenhagen, Copenhagen, Denmark \\ ${ }^{c}$ BP Exploration Operation Company Ltd., Sunbury-on-Thames, UK \\ ${ }^{d}$ Institut Laue-Langevin, Grenoble, France
}

\begin{abstract}
Bacterial anchoring to limestone rocks is thought to occur by selective adsorption of biomolecules found in the extracellular matrix, such as polysaccharides. Here we study the adsorbed structure of a model matrix polysaccharide, sodium alginate, at the calcite/water interface using neutron reflection (NR). Sodium alginate was found to form highly hydrated layers extending up to $350 \AA$ into solution at concentrations up to $2.5 \mathrm{ppm}$ (the inflection point of the adsorption isotherm). The adsorption of alginate was driven by dissolution of the calcite surface through complexation of free calcium ions. This was shown using two alginates with differing ratios of sugar residues. Alginates with a higher proportion of guluronic acid $(\mathrm{G})$ have a higher affinity for calcium ions and were found to cause the surface to dissolve to a greater extent and to adsorb more at the surface when compared to alginates with a higher proportion of
\end{abstract}


mannuronic acid (M). Adding magnesium to the high $\mathrm{G}$ alginate solution reduced dissolution of the surface and the adsorbed amount. In this work, we have shown that polysaccharide adsorption to sparingly soluble calcite interfaces is closely related to polymer conformation and affinity for free calcium ions in solution.

KEYWORDS

- Calcium Carbonate

- Calcite

- Biomineralization

- Alginate

- Polysaccharides

3 Most of the Earth's calcite $\left(\mathrm{CaCO}_{3}\right)$ is of biogenic origin from carbonaceous marine organism

4 sedimentation. Calcium carbonate biomineralisation provides structure throughout Nature from

5 avian eggshells to marine molluscs and coccoliths. ${ }^{1,2}$ The fine control of crystal morphology,

6 phase and grain size is moderated through the production of various biomolecules, which also

7 affect the mechanical properties. ${ }^{2,3}$ The precise mechanism by which these molecules interact

8 with the crystallizing medium through nucleation and growth is an area of current interest in

9 several areas, including amorphous calcium carbonate precursor phases (ACC). ${ }^{3-9}$

10 Calcium carbonate can be precipitated in several different polymorphs of varying stability. The 11 most stable polymorph under ambient conditions is calcite; it can form large defect-free crystals,

12 making it suitable as the focus of this experimental study. It is sparingly soluble in water with a 13 solubility product at room temperature of $\mathrm{K}_{\mathrm{sp}}=3.7 \times 10^{-9} \mathrm{~mol} \mathrm{dm}^{-3}{ }^{10}$ This dissolution 14 complicates the analysis of adsorption to calcite surfaces as acidic conditions can lead to a highly 
1 dynamic interface. The dissolution or precipitation of calcite is closely linked with other aqueous

2 equilibria that determine the extent of dissolution of the surface. ${ }^{11}$

3 The driving force for adsorption of polyanionic polysaccharides is expected to be the affinity of

4 the charged carboxylate groups for calcium on the positively charged calcite surface. Calcium

5 cations released from the calcite surface are sequestered to the sugar forming a complex. This

6 process in turn removes calcium from the solution shifting the equilibrium such that more

7 calcium carbonate solid is dissolved. Polyanionic polysaccharides have been shown to affect the

8 crystal growth structure of calcium carbonate by interacting with the mineral surface suggesting

9 specific interactions with the calcite surface. ${ }^{12}$ Furthermore, negatively charged sugars secreted

10 by bacteria into the extracellular matrix may aid anchoring of the cell to calcitic limestone rocks

11 in marine environments. ${ }^{13,14}$

12 Sodium alginate has been chosen for this study as a model polysaccharide due to its well13 understood structural characteristics and calcium binding properties, allowing the interplay 14 between complex-mediated surface dissolution and polymer adsorption to be investigated. ${ }^{15}$ 15 Alginates are a major structural component of marine algae and secreted by some bacteria, most 16 notably Pseudomonas aeruginosa and Azotobacter vinelandii. ${ }^{16}$ As schematically illustrated in 17 Figure 1, sodium alginate is a copolymer of two epimers, mannuronic acid (M) and guluronic 18 acid (G), which differ only by the conformation of the 1,4 glycosidic link. The two sugar 19 residues can be found either as homopolymeric blocks of each sugar or as alternating MG 20 sequences. ${ }^{17}$ The primary structure of alginate affects the macromolecular properties greatly. GG 21 blocks are rigid as the axial linkage decreases movement and provides a binding site for divalent 22 cations. Conversely, MM blocks are joined via an equatorial glycosidic linkage are therefore 
1 relatively free. ${ }^{17}$ The molecular conformation of the pairs, MM, MG and GG are included in $2 \quad$ Figure 1.

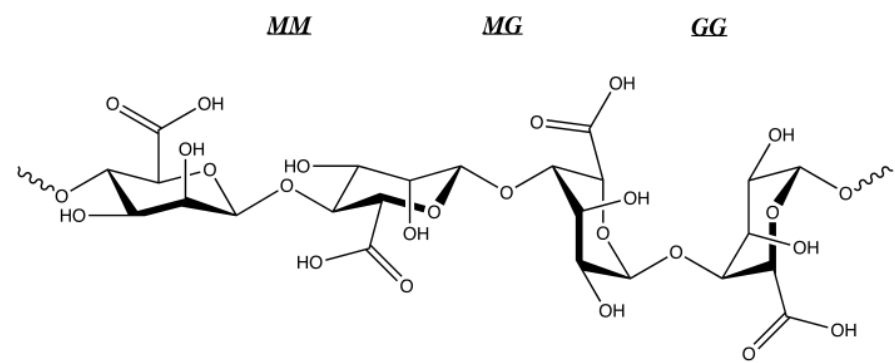

4 Figure 1: Molecular structure of the alginic acid showing the various links between the two epimers, MM, MG and 5 GG diblocks.

6 Two gram negative, alginate producing, bacteria, Pseudomonas aeruginosa and Azotobacter 7 vinelandii, secrete alginates with different compositions, macromolecular properties and 8 functions. P. aeruginosa secretes alginate as a protective envelope and adhesive molecule in 9 biofilm formation in the lung, these alginates have little to no $\mathrm{G}$ blocks. ${ }^{16}$ Conversely, $A$. 10 vinelandii, a soil bacterium that forms exopolysaccharide cysts in soil to protect from mechanical 11 stress and desiccation during dormancy, produces alginates with high ratios of GG blocks and 12 alternating sequences in the outer protective layer. ${ }^{16}$

13 The more rigid GG sections provide well-defined chelation sites, which leads to gelation on 14 addition of calcium. The more flexible MM and MG blocks deform to allow adjacent GG 15 disaccharide units to line up form a chelating cage composed of four G saccharide units. ${ }^{18}$ This 16 ability to co-ordinate is strongly linked to conformational structure, alginates with a higher 17 proportion of $\mathrm{G}$ (and $\mathrm{G}$ blocks) gel at lower concentrations of calcium ions and form stronger 18 and more brittle gels. ${ }^{19,20}$ Grant et al. defined this guluronate-Ca interaction the 'egg-box model' 19 due to the alignment of guluronate chains along a plane of calcium ions. ${ }^{17,21}$ In contrast to 
1 calcium, the binding of magnesium with alginate molecules is reported to be a non-specific

2 interaction. ${ }^{22,23}$ Magnesium alginate is soluble and does not strongly interact with any specific

3 binding sites. ${ }^{23,24}$

4 In this study we have used neutron reflection and bulk solution depletion isotherms to compare 5 the adsorption of two different sodium alginate samples with either a low (MVM) or high

6 (MVG) content of guluronate residues to calcium carbonate surfaces. Considering the higher

7 affinity of guluronate residues to calcium ions in solution, the two alginates are expected to show

8 very different surface adsorption profiles in terms of both adsorbed amount and structure.

9 Neutron reflectivity allows the measurement of complex adsorbed structures at the solid/liquid 10 interface, something which is challenging using other techniques. The study of the solid/liquid 11 interface using neutron reflection has been reasonably limited to a small number of single crystal 12 interfaces, mainly silicon, quartz and sapphire. ${ }^{25}$ Recently the number of mineral surfaces used in 13 reflection experiments has widened to include calcite, however, previous work has focused on 14 the adsorption of industrial chemicals and surfactants at the calcite/liquid interface. ${ }^{26-28}$ Here we 15 aim to investigate the adsorption of biopolymers to calcite surfaces in aqueous environments to 16 show how polymer conformation and calcium ion dissolution from the calcite surface can affect 17 adsorbed amount and structure at the interface.

\section{EXPERIMENTAL}

\section{MATERIALS}

20 All experiments were carried out using two ultrapure and well-characterised alginates (Pronova 21 UP Test kit) obtained from Novamatrix. The two alginates tested were of medium viscosity $22(>200 \mathrm{mPa}$ s) and high molecular weight $(>200 \mathrm{kDa})$ and differ by the ratio of the two sugar 
1 epimers. The high guluronate sample (Medium Viscosity Guluronate, MVG) was reported to

2 have a viscosity of $263 \mathrm{mPa}$ s and contain $69 \%$ guluronate residues. The high mannuronate

3 sample (Medium Viscosity Mannuronate, MVM) was found to have a higher viscosity (553

$4 \mathrm{mPa}$ s) with a mannuronic acid content of $54 \%$. All values quoted here were obtained from the

5 manufacturers certificate of analysis of the batch used.

6 Calcium carbonate powder ( $\geq 99 \%)$ used for adsorption isotherms and to saturate water for NR 7 experiments was purchased from Sigma Aldrich. Calcite crystals used in neutron reflection 8 experiments were optically clear Iceland Spar crystals obtained from P\&E Export Ltd, Brazil.

9 The large rhombohedral crystals were cut to a cuboid shape (40 $\times 55 \times 15 \mathrm{~mm})$ and polished to a 10 low roughness by Crystran, Poole, UK. The surface for reflectivity was the most stable $\{10 \overline{1} 4\}$ 11 face, the crystallographic plane found at the surface of the natural rhomb. Attempts were made to 12 cleave the surface rather than polish, however, it was not possible to obtain an area large enough 13 for reflectivity studies (roughly $20 \mathrm{~cm}^{2}$ ) without introducing large steps, causing the cells to leak. 14 The roughness of the polished crystals was assessed by X-ray reflectivity on a Rigaku SmartLab 15 X-ray diffractometer (ISIS, Rutherford Appleton Laboratory, Didcot, UK). This measurement 16 gave an approximate indication of the quality of the surface (data shown in supporting 17 information, Figure S1). Crystals, which had an X-ray roughness less than $15 \AA$, were then used 18 in neutron reflectivity experiments.

\section{ADSORPTION ISOTHERMS}

20 Isotherm measurements were carried out using a solution depletion batch method. $2 \mathrm{~g}$ of calcium 21 carbonate powder was homogenised with $498 \mathrm{~g}$ ultrapure water using a Silverson L4R shear 22 mixer for 10 minutes. The slurry was then weighed into centrifuge tubes and increasing amounts 
1 of alginate stock solution was added. The samples were agitated overnight and centrifuged at

$215,000 \mathrm{G}$ for 20 minutes. The supernatant was removed and filtered through a $0.45 \mu \mathrm{m}$

3 polyethersulfone syringe filter (QMX, UK). The Total Organic Carbon content of the supernatant

4 was measured using a GE InnovOx TOC Analyser. During analysis, the supernatant was

5 acidified and purged with nitrogen to remove traces of inorganic carbonates. The concentration

6 of non-purgeable carbon remaining in the supernatant was then used to calculate the adsorbed

7 amount of alginate.

\section{NEUTRON REFLECTIVITY}

9 The experiment is performed by illuminating a large flat crystal with a collimated beam of 10 neutrons, which reflect and/or refract at the solid/liquid interface. The intensity of the reflected 11 beam is then measured as a function of wavelength and reflected angle. In this experiment, the 12 D17 reflectometer at the Institut Laue-Langevin, France, ${ }^{29}$ was used in the time-of flight (TOF) 13 mode where a polychromatic beam of neutrons is directed at the sample and the wavelength 14 determined by the time taken for neutrons to reach the detector from the source. The determined 15 wavelength values are converted to a momentum transfer vector, Q, calculated from equation 1.

$$
Q=\frac{4 \pi \sin \theta}{\lambda}
$$

16 The use of the TOF method on D17 allows the entire scattering range of interest of the

17 reflectivity curve to be measured using only two incident angles, $0.6^{\circ}$ and $2.0^{\circ}$, to cover the Q

18 range of interest $\left(0.006-0.2 \AA^{-1}\right)$. To ensure no contribution from the edges of the sample, a

19 constant beam footprint of $30 \times 45 \mathrm{~mm}^{2}$ was maintained on the sample surface. The dQ/Q

20 resolution varied between $1.5-10 \%$ over the Q range measured, during data fitting a value of $4 \%$

21 resolution was used. The data reduction was performed using the COSMOS software. ${ }^{30}$ 
1 The calcite crystals were cleaned by UV-Ozone treatment (BioForce Nano Procleaner). After

2 irradiation, a small drop of filtered calcium carbonate saturated water was placed on the surface

3 to assess wettability. If the droplet spread the crystal was considered clean, placed immediately

4 against a Teflon trough and sealed in a neutron reflectivity cell (details of cell reflection sample

5 cell are given in Stocker et. al. ${ }^{26}$ ). Sample changes were carried out by draining the sample cell

6 by pipette ( $3 \mathrm{~mL}$ cell volume) and refilling in-situ with the required solution, this process was

7 repeated three times and the cell sealed with Teflon plugs.

\section{ANALYSIS OF REFLECTIVITY DATA}

9 The shape of the reflectivity curve at a single interface is determined by the surface roughness

10 and the change in neutron refractive index upon moving from one medium to the next through

11 the surface. Neutron reflection theory is outlined elsewhere. ${ }^{31}$ A particularly powerful aspect of

12 neutron reflection is the seemingly random nature of neutron scattering lengths across the

13 periodic table and between isotopes. The scattering length density (SLD) of a material is

14 calculated using equation 2 where $\mathrm{N}$ is the number density of atoms in a material and $b_{i}$ is the

15 scattering length of each nucleus.

$$
\rho=\sum N b_{i}
$$

16 The isotope effect is most clearly seen by the very different SLDs of $\mathrm{H}_{2} \mathrm{O}$ and $\mathrm{D}_{2} \mathrm{O},-0.56 \times 10^{-}$

$17{ }^{6} \AA^{-2}$ and $6.35 \times 10^{-6} \AA^{-2}$, respectively. Using isotopic substitution it is possible to study different

18 reflectivity profiles in the same chemical environment. In this work, we have measured

19 reflectivity profiles of the calcite/alginate solution in $\mathrm{H}_{2} \mathrm{O}, \mathrm{D}_{2} \mathrm{O}$, and a mixture of the two to form

20 a solution that has the same scattering length density of the calcite crystal $\left(4.69 \times 10^{-6} \AA^{-2}\right)$. This

21 combination of solution contrasts is important to constrain the structural model. By using a 
1 solution with the same SLD as the calcite, a reflected signal is only seen from the adsorbed

2 alginate (alginate $\mathrm{SLD}=2.6 \times 10^{-6} \AA^{-2}$, calculated from the expected molecular formula and

3 specific gravity).

4 The measured reflectivity profile is then analysed by comparison of the experimental data with a

5 model structure. The general approach is to constrain the structural model as much as possible to

6 fit the data. If a single layer is found not be sufficient to fit the experimental data, adsorbed

7 layers can be broken into several smaller blocks/layers to describe adsorbed structures in more

8 detail. In some cases a mathematical description of the SLD profile is appropriate, such as

9 exponential or Gaussian. ${ }^{32}$ In all of these cases, the total reflected intensity from adsorbed layers

10 is calculated using the matrix method developed by Abeles and used in reflectivity fitting

11 programs such as RasCAL. ${ }^{33}$

12 The polymer segment density distribution normal to the surface was modelled in several ways, 13 such as discrete layers, exponential decrease from the surface, or a Gaussian distribution. The 14 best fit to the data in all cases was found using the Gaussian distribution model. The SLD profile 15 through the interface was modelled by dividing a $300 \AA$ region into $10 \AA$ sections with an 16 interlayer roughness fixed to $5 \AA$ to smooth out each interface. The volume fraction of alginate 17 was then calculated in each section and converted to an SLD by assuming the rest of the layer 18 was filled with the subphase water. In all adsorbed alginate datasets it was observed that the 19 volume fraction of alginate had reached background well before the model cut off at $300 \AA$ 20 except for the $2.5 \mathrm{ppm}$ MVG where the model had to be extended to $350 \AA$ to reach background. 21 Using the modelled volume fraction distribution, an adsorbed amount was obtained from the area 22 under the Gaussian polymer segment density distribution curve. Although it was possible to fit a 23 small variation in the Gaussian profile, in all cases the distribution was found to conserve the 
1 area under the curve, within error, providing a good test of the robustness of the values for

2 adsorbed amount. Errors were calculated using the bootstrap error analysis in the RasCAL

3 program, where random parameter values are generated and a fit performed 100 times to

4 generate confidence intervals. The parameter errors were then used to calculate the error in

5 adsorbed amount, assuming the maximum and minimum possible values. The SLDs of substrate,

6 subphase, and adsorbate were fixed, where possible, according to the literature values (Table

7 S1). During the experiment it was noted that there was incomplete exchange of the liquids within

8 the cells as the SLD of the $\mathrm{H}_{2} \mathrm{O}$ subphase could not be fitted to the literature value, but rather a

9 mixture of $\mathrm{H}_{2} \mathrm{O}$ containing some $\mathrm{D}_{2} \mathrm{O}$, only when the liquid in the cell was exchanged from $\mathrm{D}_{2} \mathrm{O}$

10 to $\mathrm{H}_{2} \mathrm{O}$ in situ (despite repeated exchanges). This may be due to insufficient mixing of the two

11 liquids due to the density difference in the cell and the high contact angle between the water and 12 the hydrophobic surface of the Teflon trough.

\section{RESULTS}

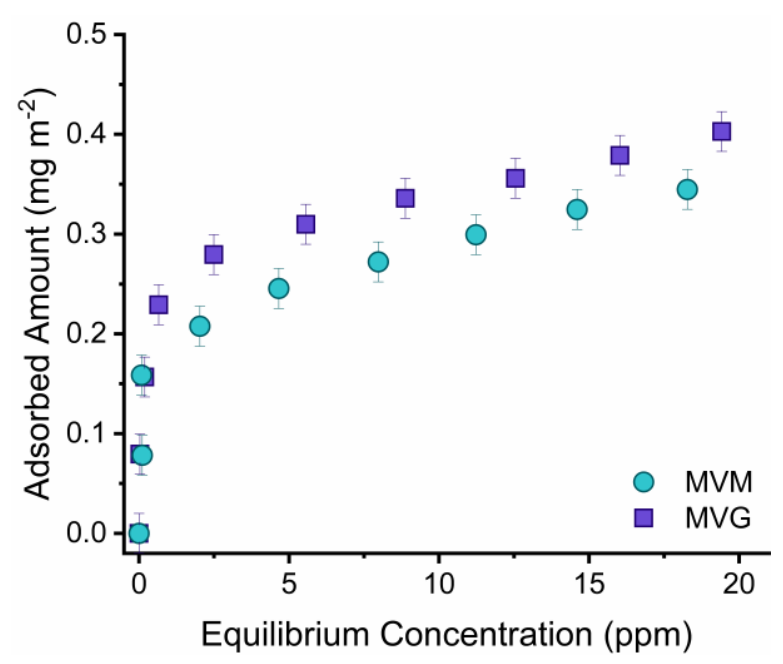

15 Figure 2: Isotherm data of sodium alginate adsorption to calcite powder in water as measured by total organic 16 carbon analysis (TOC). MVM alginate is shown as green circles and MVG as purple squares. 
1 Figure 2 presents bulk solution depletion isotherms for the adsorption of MVM (green circles)

2 and MVG (purple squares) to calcium carbonate powder. It can be seen that there is a small

3 difference between the two alginate solutions with MVG adsorbing more to the surface than

4 MVM. At low concentrations, all alginate is adsorbed as seen from a steep initial increase in

5 adsorbed amount before the turning point of the isotherm at an equilibrium concentrations of

6 roughly $2.5 \mathrm{ppm}$. At higher concentrations, the slope becomes shallower but not flat suggesting

7 that the adsorption does not form a monolayer at the surface. There may be some precipitation of

8 the alginate at higher concentrations as the calcium is dissolved into solution forming insoluble

9 calcium alginate. The interaction between the calcium carbonate surface and alginate is observed

10 to be weak due to the low adsorbed amount at equilibrium. This effect could be accentuated by

11 the sample preparation for TOC analysis. In order to remove calcium carbonate powder from the

12 supernatant, the samples are centrifuged at $15,000 \mathrm{G}$ for 20 minutes which is likely to shear off

13 any loosely bound alginate from the surface leaving only the tightly bound molecules that are

14 effectively irreversibly adsorbed by attachment at multiple points.

\section{NEUTRON REFLECTION}

16 Each calcite crystal was first measured in three saturated calcium carbonate water contrasts, $17 \mathrm{D}_{2} \mathrm{O}, \mathrm{H}_{2} \mathrm{O}$, and water contrast matched to calcite $\left(\mathrm{CMC}=4.69 \times 10^{-6} \AA^{-2}\right)$. A representative 18 dataset is shown in the supporting information (Figure S2). Previous experiments have shown 19 that the surface roughness of calcite does not increase over time in the presence of water 20 saturated with calcium carbonate powder. ${ }^{27}$ The surface cleanliness was confirmed by the 21 absence of any reflected signal above the background level in the CMC contrast (not shown).

22 Measuring the reflectivity in contrast matched water is especially useful due to the high 23 sensitivity to adsorbed layers at the surface. Unlike silicon crystals, which always have a surface 
1 oxide layer and always show a signal in contrast matched water, if the surface of calcite is

2 completely clean there will be no signal recorded. The two $\left(\mathrm{D}_{2} \mathrm{O}\right.$ and $\left.\mathrm{H}_{2} \mathrm{O}\right)$ data sets were fitted

3 simultaneously using only two fitting variables, surface roughness and $\mathrm{H}_{2} \mathrm{O}$ contrast. All bare

4 calcite crystals for the study were successfully fitted to a single interface model and the surface

5 roughness varied from $8.5 \pm 0.6 \AA$ to $9.4 \pm 0.3 \AA$.

6 Before adsorption measurements using neutron reflection it is important to completely 7 characterise the surface that the adsorbate will bind to. Unlike many other surfaces used in 8 reflection the calcite surface can be dynamic and of biogenic origin. Measurements of the bare 9 surface are therefore useful to assess the cleanliness of the substrate and provide an initial 10 roughness characterisation. When calcite is cleaved or polished, high-energy bonding sites are 11 exposed. In air, these sites are likely to be contaminated with species from the atmosphere, 12 however, this bonding of contaminants is generally weak and upon immersion, water molecules 13 compete, removing the contaminants and hydrating the surface with $\mathrm{pH}$ sensitive groups. ${ }^{11,26,34}$

\section{ALGINATE ADSORPTION}

15 Figure 3 presents experimental neutron reflectivity data of the calcite/water interface in the 16 presence of (a) $2.5 \mathrm{ppm}$ MVM and (b) $2.5 \mathrm{ppm}$ MVG alginate in three contrasts, $\mathrm{D}_{2} \mathrm{O}$ (purple 17 squares), $\mathrm{H}_{2} \mathrm{O}$ (green circles), and water contrast matched to calcite (CMC, yellow triangles). 18 Corresponding SLD profiles are provided in the supporting information (Figure S3). Alginate 19 solutions were introduced to the sample cells at concentrations of 0.5 and $1 \mathrm{ppm}$ in $\mathrm{D}_{2} \mathrm{O}$. Three 20 water contrasts were recorded for the highest concentration, $2.5 \mathrm{ppm}$. The concentration of 2.5 21 ppm was chosen to be just above the turning point of the plateau for both MVM and MVG 
1 alginates in solution depletion isotherms (Figure 2). This represents concentration where the

2 surface is expected to be covered but before the onset of multilayer formation or precipitation.
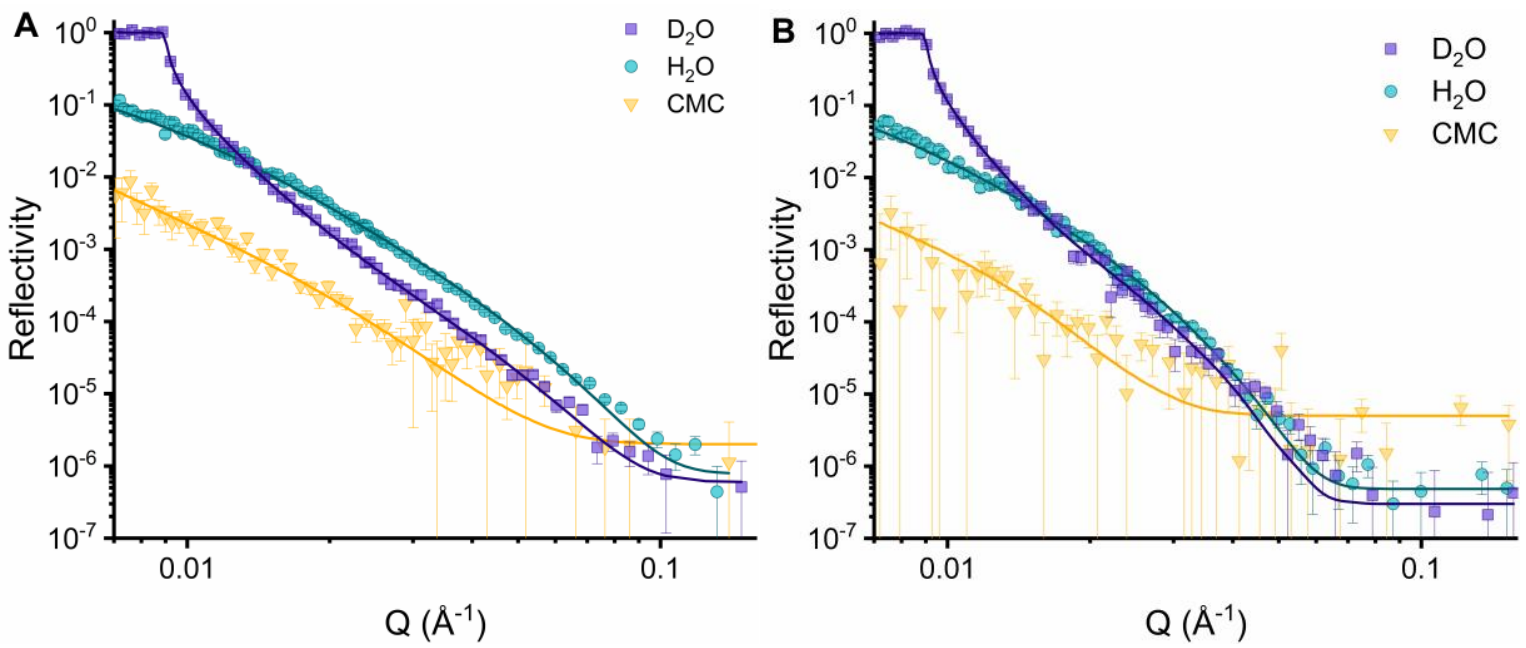

5 Figure 3: Experimental neutron reflectivity data of the calcite/water interface in the presence of A $2.5 \mathrm{ppm}$ MVM

9 drop, suggesting that the surface is roughening and/or a diffuse layer is adsorbed. A signal is also 10 seen in the contrast matched water indicating an adsorbed layer was present at the surface. This 11 signal in the contrast matched water is purely from any adsorbed material at the interface and 12 therefore has a rather low signal-to-noise ratio and large error bars. The $2.5 \mathrm{ppm}$ MVM data was 13 fitted to a Gaussian layer model with an adsorbed amount of $1.6 \pm 0.4 \mathrm{mg} \mathrm{m}^{2}$ and a surface 14 roughness of $16.1 \pm 0.9 \AA$. The volume fraction of alginate at the surface was found to be 0.098 15 showing that the adsorbed layer is highly hydrated at the interface. The volume fraction 16 decreases away from the surface into solution before reaching zero between 200 and $250 \AA$. As 
1 the concentration of MVM alginate increases, the amount adsorbed at the surface initially

2 increases and begins to level off reaching $1.6 \pm 0.4 \mathrm{mg} \mathrm{m}^{2}$ at $2.5 \mathrm{ppm} \mathrm{MVM}$. The SLD of the

3 subphase in the $\mathrm{H}_{2} \mathrm{O}$ was fitted to be higher $\left(2.28 \pm 0.05 \times 10^{-6} \AA^{-2}\right)$ than the literature value of -

$40.56 \times 10^{-6} \AA^{-2}$, due to incomplete exchange, as discussed above. Table 2 shows the surface

5 roughness and adsorbed amounts obtained from each fit to the Gaussian model described above.

8 Figure $3 \mathrm{~b}$ shows the experimental data measured for $2.5 \mathrm{ppm}$ MVG in all three water contrasts.

9 The data was fitted to a Gaussian layer model, as above, and again found to give good agreement 10 in all datasets. The SLD of the $\mathrm{H}_{2} \mathrm{O}$ contrast was again found to be higher than literature $(3.28 \pm$ $110.07 \times 10^{-6} \AA^{-2}$ ) as for MVM alginate. The polymer distribution was found to extend further into 12 solution compared to MVM, suggesting that the MVG molecule is less attracted to the calcite 13 surface. This may also be related to a greater degree of cross-linking by calcium ions compared 
1 to MVM alginate. ${ }^{17}$ The modelled roughness, $34.5 \pm 0.7 \AA$, is large and the reflected signal

2 (above the critical edge) was much lower than for other measurements and reached background

3 at lower Q. The larger roughness indicates more calcium is released into the solution to achieve

4 equilibrium when compared to MVM alginate. The amount adsorbed with concentration follows

5 a similar profile as the MVM alginate; however, the value at $2.5 \mathrm{ppm}$ is higher $\left(2.8 \pm 0.3 \mathrm{mg} \mathrm{m}{ }^{2}\right)$

6 showing that more alginate is adsorbed when the polymer contains higher ratios of guluronate 7 residues.

\section{HIGH GULUORNATE ALGINATE WITH MAGNESIUM}

9 The reflectivity study of the MVG alginate adsorption to calcite in pure water indicated 10 significant surface roughening, attributed here to sequestration of calcium by the alginate 11 molecule. It is not possible to pre-saturate the water with calcium ions due to the insolubility of 12 calcium alginate and hence transport of calcium alginate to the calcite surface for adsorption 13 would be impossible. By adding $12 \mathrm{mM} \mathrm{MgCl}_{2}$ (same concentration of calcium in saturated $14 \mathrm{CaCO}_{3}$ water) and allowing the system to equilibrate, the magnesium ions bind non-specifically 15 with the alginate, reducing the effective charge of the polymer, making it less likely to be 16 attracted to the calcite surface. ${ }^{23}$ The affinity of magnesium compared to calcium is thought to be 17 similar for $\mathrm{MM}$ and $\mathrm{MG}$ blocks but considerably smaller for GG blocks where specific 18 interactions with calcium prevail. As the alginates used in the study contain a mixture of all 19 blocks, we expect that the number of calcium ions removed from the surface will be lowered by 20 the presence of magnesium and therefore less roughening of the calcite surface upon introduction 21 to the sample cell. Magnesium ions have also been shown to bind to high energy sites on the 22 calcite surface inhibiting dissolution. ${ }^{35}$ 
2 Figure 4: Experimental neutron reflectivity data of the calcite/water interface in the presence of $2.5 \mathrm{ppm}$ MVG pre3 equilibrated with $12 \mathrm{mM} \mathrm{MgCl}_{2}$ in two contrasts, $\mathrm{D}_{2} \mathrm{O}$ (purple squares) and $\mathrm{H}_{2} \mathrm{O}$ (green circles). Calculated fits to

5 Figure 4 shows the fitted reflectivity data upon introduction of $2.5 \mathrm{ppm}$ MVG pre-equilibrated 6 with $12 \mathrm{mM} \mathrm{MgCl} 2$ in $\mathrm{D}_{2} \mathrm{O}$ (purple circles) and $\mathrm{H}_{2} \mathrm{O}$ (green circles). The corresponding SLD 7 profile is provided in the supporting information (Figure S3). It was not possible to measure the 8 CMC contrast due to time constraints of the experiment. The reflectivity profile shows a weak 9 Kiessig fringe at higher Q suggesting a more defined adsorbed layer. Upon fitting the datasets, 10 the maximum of the Gaussian polymer distribution is found to lie away from the calcite surface 11 (Figure 5a) and the adsorbed amount is lower than for MVG in pure water $(0.7 \pm 0.3$ compared 12 to $2.8 \pm 0.3 \mathrm{mg} \mathrm{m}^{-2}$ ). The surface roughness was also found to be lower $27.3 \pm 0.5 \AA$ compared 13 to $34.5 \pm 0.7 \AA$. The reduction in surface roughness by pre-saturation of the MVG with $12 \mathrm{mM}$ $14 \mathrm{MgCl}_{2}$ was not as pronounced as expected, suggesting that the affinity of MVG alginate for 15 calcium ions is high even if the charge is compensated by other divalent ions. The composition 16 of the alginate (i.e. the proportion and order of $M$ to $G$ residues) plays a greater role in the extent 17 of calcite surface roughening than the availability of divalent ions in the solution. 
A

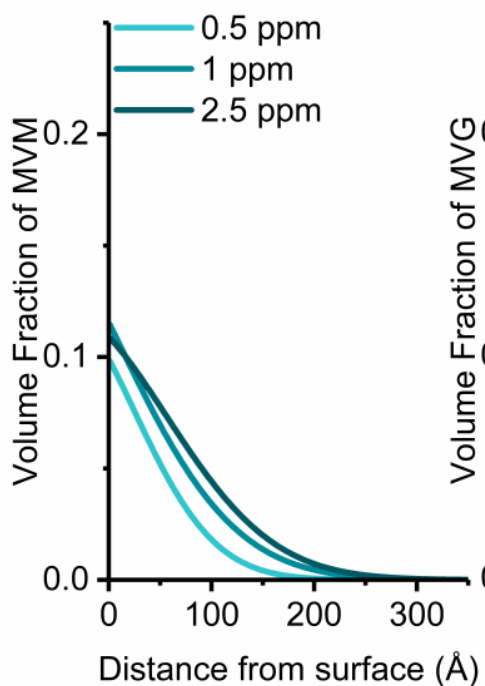

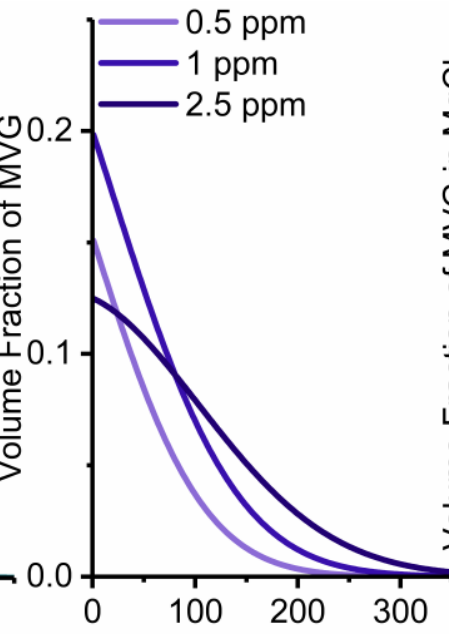

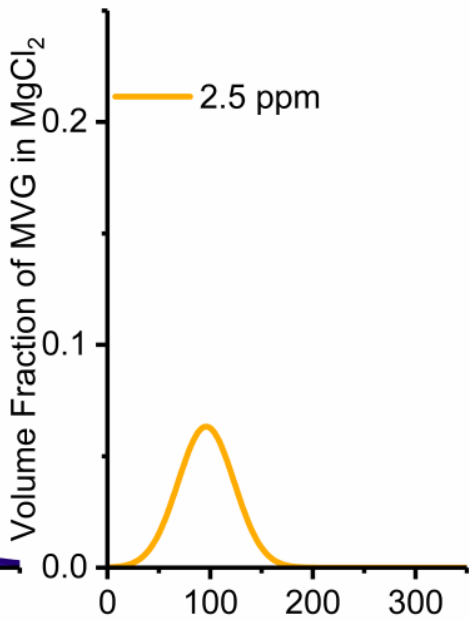

B

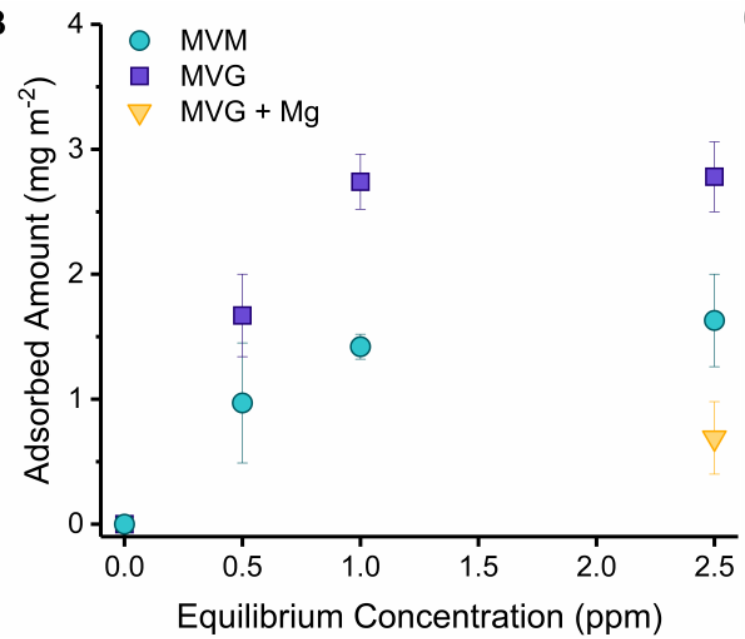

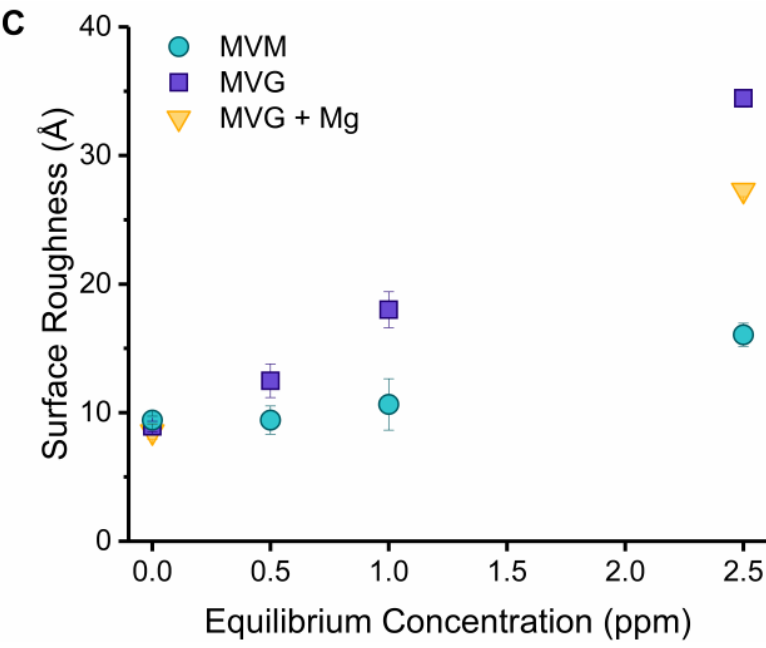


1 The data above shows the pronounced effect of the structural composition of sodium alginate on

2 both the adsorption to and roughening of the surface of calcite crystals. Figure 5 summarizes the

3 differences observed in adsorbed amounts (Fig 5b) and calcite surface roughness (Fig 5c). As

4 described above the adsorbed amount increases from zero but reached a plateau at higher

5 concentrations. The surface roughness increases with concentration, suggesting that the

6 sequestering of calcium ions to the alginate drives the surface dissolution of calcite. In the

7 reflection experiments reported here we must carefully consider the solution and surface

8 behaviour. Sodium alginate in the presence of calcium ions readily converts to calcium alginate,

9 which has a very low solubility. In order to introduce the alginate to the sample cell without

10 precipitation the reflectivity experiments must be run in pure water. However, the introduction of

11 pure water to the calcite surface increases surface dissolution and roughening. ${ }^{26}$ The technique of

12 neutron reflection requires very flat surfaces for a good reflected signal and hence any

13 dissolution should be kept small. However, we also exploit the sensitivity of the reflection to this

14 roughening as an ideal way of probing the surface dissolution. In previous studies, calcite in

15 contact with pure water was found to roughen quickly before plateauing at a roughness $2 \mathrm{~nm}$

16 greater than the original surface. ${ }^{26,36}$

\section{DISCUSSION}

18 This work is able to report on significant differences in the adsorption and surface roughening

19 between the two investigated alginates: the alginate with the higher proportion of guluronate 20 residues (MVG) is found increase calcite dissolution and shows a higher adsorption to the calcite 21 surface compared to the alginate with a lower proportion of guluronate (MVM). As discussed 22 above, alginate in the presence of calcium is reported to crosslink preferentially between GG 23 units causing gelation and insolubility known as the 'egg-box' model. ${ }^{17,21}$ Therefore, the higher 
2 However, the difference in M:G ratios between the two alginates is not large (46 \% vs. $69 \%$

3 guluronate residues) compared to the observed effects. The overall composition of the alginate

4 does not tell us the sequence of sugar residues, which can consist of three different repeat unit

5 sections, GG blocks, MM blocks or alternating MG blocks. The two alginates used in this study

6 have not been tested for the proportion of each of these pair wise sections. Therefore, the MVG

7 alginate may have a significantly higher proportion of the $G$ residues in blocks of pure

8 guluronate (i.e. GG) rather than in alternating MG sections. GG blocks are the most effective at

9 crosslinking to form the 'egg box' structure that causes the molecule to become insoluble and

10 inflexible. Furthermore, higher proportions of $\mathrm{G}$ blocks may favour polymer-polymer 11 conformations rather than polymer-surface interactions and a more extended polymer 12 conformation reaching out from the surface as we see for the $2.5 \mathrm{ppm}$ MVG alginate where the 13 polymer extends much farther out into solution as compared to MVM.

14 Addition of magnesium ions to the alginate solutions before introduction to the cell was found to 15 reduce the alginate binding and surface roughness. This effect is probably due to lower effective 16 charge of the alginate molecule by non-specific interactions with magnesium ions and lower 17 binding of calcium leading to less ion removal from the calcite surface. ${ }^{22}$. In addition, the pre18 equilibrated alginate formed a different adsorption profile with maximum adsorbed amount lying 19 away from the surface as compared to that obtained from alginate adsorbed from pure water 20 solutions where the maximum was found to lie at the surface of the calcite.

21 Polyelectrolyte adsorption to oppositely charged surfaces in low ionic strength solutions is 22 complex and depends on a number of factors, including effective charge of the molecule due to 23 specific ion binding, ionic strength, and surface charge. ${ }^{37,38}$ At the interface, polyelectrolytes can 
1 form trains, loops, and tails, in differing ratios depending on the system of study. For lower

2 polyelectrolyte charge densities, as would be expected for calcium saturated alginate in low salt

3 conditions, loop and tail adsorption is favoured. ${ }^{37,39}$ Entropic effects are also expected to play a

4 major role in the adsorption of oppositely charged polyelectrolyte adsorption through the release

5 of surface bound charge compensating counterions. ${ }^{40}$ Also, in low ionic strength conditions the

6 electrical double layer would extend far enough to trap molecules electrostatically.

7 There is a large body of work attempting to describe the interactions between alginate and

8 calcium and its effect on calcium carbonate biomineralisation and dissolution. Experimental and

9 theoretical treatments of the 'egg box' model have shown the process to occur via three stages

10 during which mono then bi-dentate binding is seen before larger aggregations form, linked by

11 calcium ions. ${ }^{15,41}$ Borgogna et. al. reported the specific binding of calcium ions to alginate occurs

12 even at low concentration of calcium equilibrated with water. ${ }^{42}$ The binding proceeds via a tilted 13 egg-box model to minimise the repulsive interactions of the negative carboxylic acid groups.

14 Experiments at the interface are more scarce, Perry et. al. studied the dissolution behaviour of 15 calcite in the presence of alginate and reported that etch pits on the surface were lengthened 16 along the obtuse angle of the rhombohedral pit due to bidentate binding of the high energy 17 calcium at the edge of the pit to a GG dimer. ${ }^{43,44}$ In these experiments, the proportion of 18 guluronate residues is suggested to be the key to the increased interactions with calcium ions.

19 The present work agrees well with the solution and adsorption data from previous studies where 20 the high guluronate alginate (MVG) both adsorbs more to the calcite surface and dissolves the 21 surface to a greater extent than the same concentration of alginate with a lower guluronate 22 content (MVM). By studying this complex system using neutron reflection we were able to study 23 not only the adsorbed amount but also how the alginate adsorbed structure is affected by sugar 
1 chain composition and the addition of magnesium. We find that the adsorbed amount is greatly

2 reduced when studying bulk isotherms that have been centrifuged, indicating that $90 \%$ of the

3 adsorbed polymer in the static system is only weakly attached to the surface. We also find that

4 higher concentrations of MVG, with and without magnesium ions, extend further out into

5 solution compared to low concentrations and low guluronate alginates suggesting more loop and

6 tail formation and less affinity for the calcite surface. These results can be used to understand the

7 formation of highly charged polysaccharide coatings and hydrogels in the presence of divalent

8 cations for biodegradable tissue scaffolds or injectable biomaterials. ${ }^{45-47}$ Future studies in

9 marine-like salt conditions as well as more complex extracellular matrix polysaccharides would

10 build on this knowledge to understand how bacterial anchoring occurs to limestone rocks and 11 soils.

\section{CONCLUSION}

13 Neutron reflectivity was able to demonstrate processes occurring during adsorption of alginate to 14 calcite surfaces of interest to studies of bacterial anchoring to limestone rocks and 15 biomineralisation. The system is extremely complex in terms of adsorption, solution chemistry 16 and ion complexation. However, by careful control of the solution composition we are able to 17 identify that these polymers are observed to form thick, highly hydrated layers at the surface. 18 The dissolution of the calcite crystal due to polymer complexation was significant and was 19 followed on an Ångström scale without perturbing or removing the adsorbed molecules. The 20 conformation of the 1,4- $\alpha$ linkage of the polysaccharide was found to alter the adsorbed amount 21 and structure of the molecule at the interface. Alginate molecules containing high proportions of 22 guluronate sugar residues adsorbed more and removed more calcium ions from the calcite 23 surface when compared to alginate with a lower proportion of guluronate. This work shows the 
1 importance of polymer conformation and ion affinity on adsorption to dynamic dissolving calcite 2 interfaces.

4 AUTHOR INFORMATION

5 Corresponding Author

6 * Corresponding author. E-mail address: kathryn.browning@sund.ku.dk Tel No:+45 42494825

7 Address: Department of Pharmacy, University of Copenhagen, Universitetsparken 2,

8 Copenhagen 2100, Denmark

\section{$9 \quad$ Author Contributions}

10 KLB, INS, and SMC designed the study. All authors were involved in performing the 11 experiments and in the interpretation of the experimental results. The manuscript was written 12 through contributions of all authors who have approved the final version of the manuscript.

\section{ACKNOWLEDGMENTS}

14 We acknowledge the Partnership for Soft Condensed Matter (PSCM) for the use of the 15 UV/ozone cleaner and the laboratory. We thank the Materials Characterisation Lab at the ISIS 16 Neutron and Muon Source, UK, for use of the x-ray reflectometer and Liv Sofia Elinor 17 Damgaard for help with the XRR data. We thank the ILL for the beam time to study this system 18 (experiment number: 9-10-1140). Martin Malmsten is gratefully acknowledged for helpful 19 discussions during the manuscript preparation. We would like to thank BP Plc. (KLB and INS) 20 and Leo Foundation (Grant No. 2016-11-01, KLB) for funding.

\section{REFERENCES}

22 (1) Hernández-Hernández, A.; Vidal, M. L.; Gómez-Morales, J.; Rodríguez-Navarro, A. B.; 
Labas, V.; Gautron, J.; Nys, Y.; García Ruiz, J. M. Influence of Eggshell Matrix Proteins on the Precipitation of Calcium Carbonate (CaCO3). J. Cryst. Growth 2008, 310 (7-9), 1754-1759. https://doi.org/10.1016/j.jcrysgro.2007.11.170.

(2) Meldrum, F. C. Calcium Carbonate in Biomineralisation and Biomimetic Chemistry. Int.

Mater. Rev. 2003, 48 (3), 187-224. https://doi.org/10.1179/095066003225005836.

(3) Mann, S. The Chemistry of Form. Angew. Chemie 2000, 39 (19), 3392-3406. https://doi.org/10.1002/1521-3773(20001002)39:19<3392::aid-anie3392>3.0.co;2-m.

(4) Addadi, L.; Raz, S.; Weiner, S. Taking Advantage of Disorder: Amorphous Calcium Carbonate and Its Roles in Biomineralization. Adv. Mater. 2003, 15 (12), 959-970. https://doi.org/10.1002/adma.200300381.

(5) Wolf, S. E.; Lieberwirth, I.; Natalio, F.; Bardeau, J. F.; Delorme, N.; Emmerling, F.; Barrea, R.; Kappl, M.; Marin, F. Merging Models of Biomineralisation with Concepts of Nonclassical Crystallisation: Is a Liquid Amorphous Precursor Involved in the Formation of the Prismatic Layer of the Mediterranean Fan Mussel Pinna Nobilis? Faraday Discuss. 2012, 159 (0), 433-448. https://doi.org/10.1039/c2fd20045g.

(6) Xu, A. W.; Ma, Y.; Cölfen, H. Biomimetic Mineralization. J. Mater. Chem. 2007, 17 (5), 415-449. https://doi.org/10.1039/b611918m.

(7) Arias, J. L.; Fernández, M. S. Polysaccharides and Proteoglycans in Calcium CarbonateBased Biomineralization. Chem. Rev. 2008, 108 (11), 4475-4482. https://doi.org/10.1021/cr078269p.

(8) Yang, M.; Stipp, S. L. S.; Harding, J. Biological Control on Calcite Crystallization by Polysaccharides. Cryst. Growth Des. 2008, $8 \quad$ (11), 4066-4074. https://doi.org/10.1021/cg800508t. 
1 (9) Meldrum, F. C.; Sear, R. P. Now You See Them. Science (80-. ). 2008, 322 (5909), 18021803. https://doi.org/10.1126/science.1167221.

(10) Haynes, W. M. CRC Handbook of Chemistry and Physics: A Ready-Reference Book of Chemical and Physical Data; CRC Press, 2011.

(11) Stumm, W.; Morgan, J. J. Aquatic Chemistry: An Introduction Emphasizing Chemical Equilibria in Natural Waters; Wiley, 1981.

(12) Butler, M. F.; Glaser, N.; Weaver, A. C.; Kirkland, M.; Heppenstall-Butler, M. Calcium Carbonate Crystallization in the Presence of Biopolymers. Cryst. Growth Des. 2006, 6 (3), 781-794. https://doi.org/10.1021/cg050436w.

(13) Vu, B.; Chen, M.; Crawford, R.; Ivanova, E. Bacterial Extracellular Polysaccharides Involved in Biofilm Formation. Molecules 2009, 14 (7), 2535-2554. https://doi.org/10.3390/molecules14072535.

(14) Decho, A. W. Overview of Biopolymer-Induced Mineralization: What Goes on in $\begin{array}{llllll}\text { Biofilms? } & \text { Ecol. } & \text { Eng. } & \mathbf{2 0 1 0}, & 36 & \text { (2), }\end{array}$ https://doi.org/10.1016/j.ecoleng.2009.01.003.

(15) Fang, Y.; Al-Assaf, S.; Phillips, G. O.; Nishinari, K.; Funami, T.; Williams, P. A.; Li, A. Multiple Steps and Critical Behaviors of the Binding of Calcium to Alginate. J. Phys. Chem. B 2007, 111 (10), 2456-2462. https://doi.org/10.1021/jp0689870.

(16) Sabra, W.; Zeng, A. P.; Deckwer, W. D. Bacterial Alginate: Physiology, Product Quality and Process Aspects. Applied Microbiology and Biotechnology. 2001, pp 315-325. https://doi.org/10.1007/s002530100699.

(17) Smidsrød, O. Molecular Basis for Some Physical Properties of Alginates in the Gel State. Faraday Discuss. Chem. Soc. 1974, 57 (0), 263-274. 
https://doi.org/10.1039/DC9745700263.

2
(18) Donati, I.; Holtan, S.; Mørch, Y. A.; Borgogna, M.; Dentini, M.; Skjåk-Bræk, G. New Hypothesis on the Role of Alternating Sequences in Calcium-Alginate Gels. Biomacromolecules 2005, 6 (2), 1031-1040. https://doi.org/10.1021/bm049306e.

(19) Haug, A.; Myklestad, S.; Larsen, B.; Smidsrød, O.; Eriksson, G.; Blinc, R.; Paušak, S.; Ehrenberg, L.; Dumanović, J. Correlation between Chemical Structure and Physical Properties of Alginates. Acta Chem. Scand. 1967, 21, 768-778. https://doi.org/10.3891/acta.chem.scand.21-0768.

(20) Gacesa, P. Alginates. Carbohydr. Polym. 1988, $8 \quad$ (3), 161-182. https://doi.org/10.1016/0144-8617(88)90001-X.

(21) Grant, G. T.; Morris, E. R.; Rees, D. A.; Smith, P. J. C.; Thom, D. Biological Interactions between Polysaccharides and Divalent Cations: The Egg-Box Model. FEBS Lett. 1973, 32 (1), 195-198. https://doi.org/10.1016/0014-5793(73)80770-7.

(22) Donati, I.; Cesàro, A.; Paoletti, S. Specific Interactions versus Counterion Condensation. 1. Nongelling Ions/Polyuronate Systems. Biomacromolecules 2006, 7 (1), 281-287. https://doi.org/10.1021/bm050646p.

(23) Donati, I.; Asaron, F.; Paoletti, S. Experimental Evidence of Counterion Affinity in Alginates: The Case of Nongelling Ion Mg2+. J. Phys. Chem. B 2009, 113 (39), 1287712886. https://doi.org/10.1021/jp902912m.

(24) Donati, I.; Benegas, J. C.; Cesàro, A.; Paoletti, S. Specific Interactions versus Counterion Condensation. 2. Theoretical Treatment within the Counterion Condensation Theory. Biomacromolecules 2006, 7 (5), 1587-1596. https://doi.org/10.1021/bm050981d.

23 (25) Penfold, J.; Thomas, R. K. The Application of the Specular Reflection of Neutrons to the 
Study of Surfaces and Interfaces. Journal of Physics: Condensed Matter. IOP Publishing 1990, pp 1369-1412. https://doi.org/10.1088/0953-8984/2/6/001.

Stocker, I. N.; Miller, K. L.; Lee, S. Y.; Welbourn, R. J. L.; Mannion, A. R.; Collins, I. R.; Webb, K. J.; Wildes, A.; Kinane, C. J.; Clarke, S. M. Neutron Reflection at the CalciteLiquid Interface; Berlin, Heidelberg, 2012; Vol. 139, pp 91-99. https://doi.org/10.1007/978-3-642-28974-3_16.

(27) N. Stocker, I.; L. Miller, K.; Y. Lee, S.; R. Collins, I.; M. Clarke, S.; J. Webb, K.; J. Kinane, C.; Wildes, A. Adsorption at the Calcite - Liquid Interface with Molecular Precision. In IOR 2011 - 16th European Symposium on Improved Oil Recovery; EAGE Publications BV, 2014. https://doi.org/10.3997/2214-4609.201404793.

(28) Stocker, I. N. I. N.; Miller, K. L. K. L.; Welbourn, R. J. L. R. J. L.; Clarke, S. M. S. M.; Collins, I. R. I. R.; Kinane, C.; Gutfreund, P. Adsorption of Aerosol-OT at the Calcite/Water Interface - Comparison of the Sodium and Calcium Salts. J. Colloid Interface Sci. 2014, 418, 140-146. https://doi.org/10.1016/j.jcis.2013.11.046.

(29) Saerbeck, T.; Cubitt, R.; Wildes, A.; Manzin, G.; Andersen, K. H.; Gutfreund, P. Recent Upgrades of the Neutron Reflectometer D17 at ILL. J. Appl. Crystallogr. 2018, 51 (2), 249-256. https://doi.org/10.1107/S160057671800239X.

(30) Gutfreund, P.; Saerbeck, T.; Gonzalez, M. A.; Pellegrini, E.; Laver, M.; Dewhurst, C.; Cubitt, R. Towards Generalized Data Reduction on a Chopperbased Time-of-Flight Neutron Reflectometer. J. Appl. Crystallogr. 2018, $51 \quad$ (3), 606-615. https://doi.org/10.1107/S160057671800448X.

(31) Sivia, D. S. Elementary Scattering Theory; Oxford University Press, 2013. https://doi.org/10.1093/acprof:oso/9780199228676.001.0001. 
1 (32) Cosgrove, T. Volume-Fraction Profiles of Adsorbed Polymers. J. Chem. Soc. Faraday

Trans. 1990, 86 (9), 1323-1332. https://doi.org/10.1039/FT9908601323.

(33) RasCAL download | SourceForge.net https://sourceforge.net/projects/rscl/ (accessed Feb 20, 2020).

(34) Madsen, L. Calcite: Surface Charge. In Encyclopedia of Surface and Colloid Science, Third Edition; Somasundaran, P., Ed.; Taylor \& Francis Group: New York, 2006; pp 1084-1096. https://doi.org/10.1081/E-ESCS3-120000648.

(35) Compton, R. G.; Brown, C. A. Inhibition of Calcite Dissolution/Precipitation: Mg2+ $\begin{array}{llllllll}\text { Cations. } & \text { J. } & \text { Colloid Interface } & \text { Sci. 1994, } 165 & \text { (2), 445-449. }\end{array}$ https://doi.org/10.1006/jcis.1994.1248.

(36) Bisschop, J.; Dysthe, D. K.; Putnis, C. V.; Jamtveit, B. In Situ AFM Study of the Dissolution and Recrystallization Behaviour of Polished and Stressed Calcite Surfaces. Geochim. Cosmochim. Acta 2006, $70 \quad$ (7), 1728-1738. https://doi.org/10.1016/j.gca.2005.12.013.

(37) G. Fleer J.M.H.M. Scheutjens, T. Cosgrove and B. Vincent, M. A. C. S. Polymer at Interfaces; Springer Netherlands, 1998. https://doi.org/https://www.springer.com/gp/book/9780412581601.

(38) Kawaguchi, M.; Takahashi, A. Polymer Adsorption at Solid-Liquid Interfaces. Adv. Colloid Interface Sci. 1992, 37 (3-4), 219-317. https://doi.org/10.1016/00018686(92)80085-C.

(39) Lee, E. M.; Thomas, R. K.; Rennie, A. R. Reflection of Neutrons from a Polymer Layer Adsorbed at the Quartz-Water Interface. EPL 1990, 13 (2), 135-141. https://doi.org/10.1209/0295-5075/13/2/007. 
1 (40) V. Klitzing, R. Internal Structure of Polyelectrolyte Multilayer Assemblies. Physical Chemistry Chemical Physics. The Royal Society of Chemistry November 8, 2006, pp 5012-5033. https://doi.org/10.1039/b607760a.

(41) Braccini, I.; Pérez, S. Molecular Basis of Ca2+-Induced Gelation in Alginates and Pectins: The Egg-Box Model Revisited. Biomacromolecules 2001, 2 (4), 1089-1096. https://doi.org/10.1021/bm010008g.

(42) Borgogna, M.; Skjåk-Bræk, G.; Paoletti, S.; Donati, I. On the Initial Binding of Alginate by Calcium Ions. The Tilted Egg-Box Hypothesis. J. Phys. Chem. B 2013, 117 (24), 7277-7282. https://doi.org/10.1021/jp4030766.

(43) Perry IV, T. D.; Duckworth, O. W.; McNamara, C. J.; Martin, S. T.; Mitchell, R. Effects of the Biologically Produced Polymer Alginic Acid on Macroscopic and Microscopic Calcite Dissolution Rates. Environ. Sci. Technol. 2004, 38 (11), 3040-3046. https://doi.org/10.1021/es035299a.

(44) Perry; Duckworth, O. W.; Kendall, T. A.; Martin, S. T.; Mitchell, R. Chelating Ligand Alters the Microscopic Mechanism of Mineral Dissolution. J. Am. Chem. Soc. 2005, 127 (16), 5744-5745. https://doi.org/10.1021/ja042737k.

Douglas, T. E. L.; Sobczyk, K.; Łapa, A.; Włodarczyk, K.; Brackman, G.; Vidiasheva, I.; Reczyńska, K.; Pietryga, K.; Schaubroeck, D.; Bliznuk, V.; et al. Ca:Mg:Zn:CO 3 and Ca:Mg:CO 3-Tri-and Bi-Elemental Carbonate Microparticles for Novel Injectable SelfGelling Hydrogel-Microparticle Composites for Tissue Regeneration Related Content. Biomed. Mater. 2017, 12 (2), 025015. https://doi.org/10.1088/1748-605X/aa6200.

Ren, B.; Chen, X.; Du, S.; Ma, Y.; Chen, H.; Yuan, G.; Li, J.; Xiong, D.; Tan, H.; Ling, Z.; et al. Injectable Polysaccharide Hydrogel Embedded with Hydroxyapatite and Calcium 


\section{E-MAIL ADDRESSES OF AUTHORS}

15 Kathryn Browning: kathryn.browning@sund.ku.dk

16 Isabella Stocker: isabella.stocker@cantab.net

17 Philipp Gutfreund: gutfreund@ill.fr

18 Stuart Clarke: stuart@bpi.cam.ac.uk https://doi.org/10.1039/c9tb01287g.

VS.
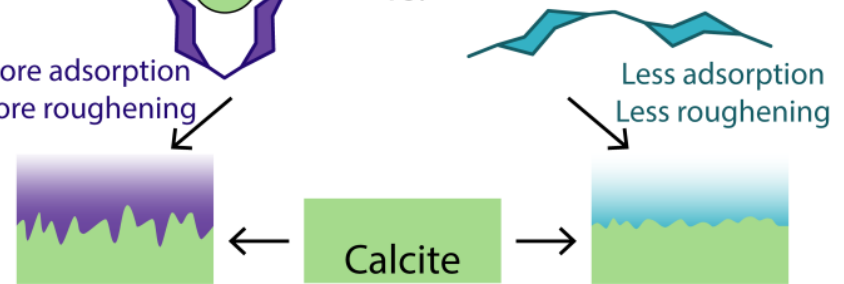

Carbonate for Drug Delivery and Bone Tissue Engineering. Int. J. Biol. Macromol. 2018, 118, 1257-1266. https://doi.org/10.1016/j.ijbiomac.2018.06.200.

(47) Saveleva, M.; Vladescu, A.; Cotrut, C.; Van Der Meeren, L.; Surmeneva, M.; Surmenev, R.; Parakhonskiy, B.; Skirtach, A. G. The Effect of Hybrid Coatings Based on Hydrogel, Biopolymer and Inorganic Components on the Corrosion Behavior of Titanium Bone Implants. J. Mater. Chem. $\quad B \quad$ 2019, $7 \quad$ (43), $\quad 6778-6788$.

19 
7:Supplementary Material
Click here to download 7:Supplementary Material: supporting information revision.docx

7:Supplementary Material
Click here to download 7:Supplementary Material: supporting information revision.docx

(c)

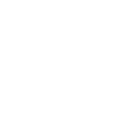

(2)

$\sqrt{2}$

(1)

(1)

(1)

(1)

(1)

.

.

.

.

.

.

.

.

.

.

.

.

.

.

.

.

.

.

.

.

.

.

.

.

.

.

. 
Highlights

- Sodium alginate adsorption to calcite in water was studied using neutron reflection

- Alginate formed highly hydrated layers at the surface with Gaussian distribution

- Alginates with high guluronic acid adsorbed more than with high mannuronic acid

- High guluronate alginates roughened the surface more due to complexation of calcium

- Added magnesium ions caused lower roughening and adsorption of alginate to calcite 


\section{Declaration of interests}

$\bigotimes$ The authors declare that they have no known competing financial interests or personal relationships that could have appeared to influence the work reported in this paper.

$\square$ The authors declare the following financial interests/personal relationships which may be considered as potential competing interests:

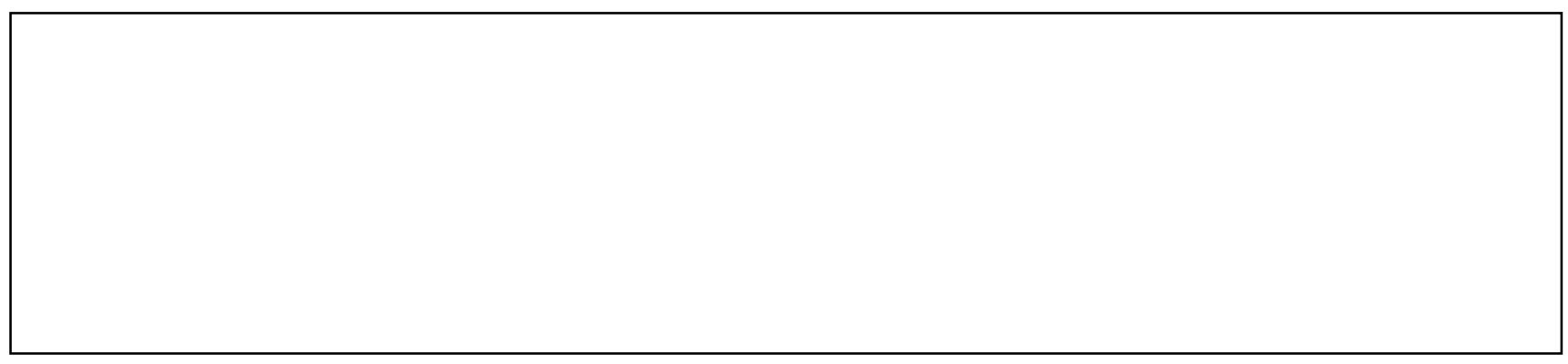


Credit Statement: The effect of alginate composition on adsorption to calcium carbonate surfaces

Kathryn Louise Browning Conceptualization, Methodology, Software, Investigation, Writing Original Draft, Visualization

Isabella N Stocker Conceptualization, Methodology, Investigation, Writing - Review \& Editing

Philipp Gutfreund Software, Investigation, Resources, Data Curation, Writing - Review \& Editing

Stuart M Clarke Conceptualization, Methodology, Software, Investigation, Writing - Review \& Editing, Supervision, Funding Aquisition 